\title{
Circular RNAs in Cancer: emerging functions in hallmarks, stemness, resistance and roles as potential biomarkers
}

Min Su ${ }^{1,2,4 \dagger}$, Yuhang Xiao ${ }^{2,3+}$, Junliang Ma', Yanyan Tang ${ }^{2}$, Bo Tian ${ }^{1}$, Yuqin Zhang ${ }^{3}$, Xu Li', Zhining Wu', Desong Yang ${ }^{1}$, Yong Zhou ${ }^{1}$, Hui Wang ${ }^{2}$, Qianjin Liao ${ }^{2,4^{*}}$ and Wenxiang Wang ${ }^{1,2^{*}}$

\begin{abstract}
Circular RNAs (circRNAs) are a class of RNA molecules with closed loops and high stability. CircRNAs are abundantly expressed in eukaryotic organisms and exhibit both location- and step-specificity. In recent years, circRNAs are attracting considerable research attention attributed to their possible contributions to gene regulation through a variety of actions, including sponging microRNAs, interacting with RNA-binding proteins, regulating transcription and splicing, and protein translation. Growing evidence has revealed that circRNAs play critical roles in the development and progression of diseases, especially in cancers. Without doubt, expanding our understanding of circRNAs will enrich knowledge of cancer and provide new opportunities for cancer therapy. In this review, we provide an overview of the characteristics, functions and functional mechanisms of circRNAs. In particular, we summarize current knowledge regarding the functions of circRNAs in the hallmarks, stemness, resistance of cancer, as well as the possibility of circRNAs as biomarkers in cancer.
\end{abstract}

Keywords: CircRNAs, Cancer, Function, Hallmarks, Stemness, Resistance, Biomarker

\section{Introduction}

CircRNAs are a class of single-stranded closed circular RNA molecules that lack $5^{\prime}-3^{\prime}$ ends and poly (A) tails [1]. Four decades have elapsed since circular RNAs (circRNAs) were first found in plant-based viruses in 1976 [2]. CircRNAs were later found in eukaryotes as an endogenous RNA splicing product in 1979 and in humans following hepatitis delta virus infection in 1986 [3, 4]. However, circRNAs were initially considered as functionless byproducts of aberrant RNA splicing and thus have not garnered sufficient scientific attention. In 2012, Salzman et al. [5] identified the abundance of circRNA species in both normal and mammalian cells and

\footnotetext{
* Correspondence: hnchw11@163.com; liaoqianjin@hnszlyy.com

${ }^{+}$Min Su and Yuhang Xiao contributed equally to this work.

${ }^{2}$ Hunan Key Laboratory of Translational Radiation Oncology, Hunan Cancer Hospital and The Affiliated Cancer Hospital of Xiangya School of Medicine, Central South University, Changsha, China

${ }^{1}$ Department of the 2nd Department of Thoracic Surgery, Hunan Cancer Hospital and The Affiliated Cancer Hospital of Xiangya School of Medicine, Central South University, Changsha, Hunan 410013, People's Republic of China

Full list of author information is available at the end of the article
}

revealed that more than $10 \%$ of expressed genes are able to produce circRNAs. In 2013, Hansen et al. [6] and Memczak et al. [7] reported that circular transcripts of cerebellar degeneration-related protein 1 antisense RNA (CDR1as, also known as ciRS-7) can serve as miRNA sponges for miR-7. These works transformed circRNAs into a focal point of scientific research and rising stars in the noncoding RNA field.

In recent years, following the development and application of high-throughput deep RNA sequencing and bioinformatics technology, circRNAs have been found to be widespread in eukaryotic cells and dynamically expressed in various developmental stages and physiological conditions $[8,9]$. A large number of researchers have demonstrated that circRNAs are correlated with the pathogenesis of various human diseases, including nervous system disorders [10], cardiovascular disorders [11], Alzheimer's disease [12], osteoarthritis [13], diabetes [14], silicosis [15] and cancer [16, 17]. In particular, circRNAs have been reported to play critical roles in cancer growth, metastasis, stemness and resistance to therapy $[18,19]$. Natural circRNA, which plays an 
important role in the RNA interaction network, was proven to be extremely abundant, relatively stable, diverse and conserved [8]. Emerging evidence suggests that circRNAs are responsible for complicated functions such as serving as endogenous RNAs to sponge miRNAs, regulating expression of parental genes, modulating alternative splicing, regulating RNA-protein interactions, and acting as scaffolds in the assembly of protein complexes $[20,21]$. In this review, we describe the characteristics, functions and functional mechanisms of circRNA. Specifically, we discuss the role of circRNA in the hallmarks, stemness, resistance of cancer, as well as the possibility of circRNAs as biomarkers in cancer.

\section{Characteristics and biogenesis of circRNAs}

According to recent research, circRNAs are typically generated from one to five exons with length between a few hundred to thousands of nucleotides (nt) [22, 23]. There are several important properties of circRNAs generated by back-splicing: (1) circRNAs have a closed ring structure-without either $5^{\prime}-3^{\prime}$ polarity or a polyadenylated tail-and are thus insusceptible to degradation by exonucleases and much more stable than linear RNA [24]; (2) circRNAs are widely expressed in eukaryotic cells, and more than one million circRNAs exist in human tissues as detected by high-throughput sequencing [25]; (3) circRNAs primarily reside in the cytoplasm, whereas a small number of circRNAs are located in the nucleus [7]; (4) most circRNAs have highly conserved sequences between different species [26]; (5) circRNAs exhibit tissue-specific and dynamic developmental stage-expression patterns [9]; (6) circRNAs play a regulatory role at the level of transcription or posttranscription [7].

Both circRNAs and linear RNAs are originated from precursor mRNAs (pre-mRNAs), but in contrast to linear RNAs that are generated by classical splicing, circRNAs are usually formed by back-splicing [8]. CircRNAs can be derived from all regions of the genome, including intergenic, intronic, antisense and untranslational regions [7]. There are three major categories of circRNAs base on their origin: exonic circRNAs (ecircRNAs), exon-intron circRNAs (EIciRNAs), and circular intronic RNAs (ciRNAs) [27]. EcircRNAs are derived from exons and account for the main part of identified circRNAs [28]. Two models of ecircRNA formation have been proposed [8]. (1) Iariat-driven circularization model: the introns in a lariat intermediate that consists several exons and introns are removed, followed by the connection between the 3 ' splice site of an upstream exon (splice acceptor) and the $5^{\prime}$ splice site of a downstream of exon (splice donor), resulting in the formation of ecircRNAs. (2) Intron pairing-driven circularizing model: a circular structure is formed by base-paring between reverse complementary sequences (such as Alu repeats, which are short DNA stretches initially characterized by the action of the Arthrobacterluteus restriction endonuclease) across exon-flanking introns. Intron paring place the splice sites close to each other, followed by back-splicing of premRNAs and exon circularization. Unlike ecircRNAs, EIciRNAs retain the introns that are not spliced out completely [29]. Pre-mRNAs that contain flanking Alu complementary pairs or flanking complementary sequence pairs other than Alu could facilitate the production of EIciRNAs [29]. In addition, ciRNAs are derived from intron lariats that escape the normal intron debranching and degradation [30]. The formation of ciRNAs are dependent on the presence of a $7 \mathrm{nt}$ GU-rich sequence near the $5^{\prime}$ splicing site and a $11 \mathrm{nt} C$-rich motifs near the 3' branch point site. Up to today, several sequence features have been indicated to influence the biosynthesis of circRNA, such as length of intron and exon, repetitive sequences and RNA-binding proteins (RBPs) [31, 32]. The RBPs that include muscleblind (MBL), quaking (QKI), SR protein, adenosine deaminases that act on RNA (ADAR1), fused in sarcoma (FUS), heterogeneous nuclear ribonucleoprotein (hnRNP), NF90/NF110, heterogeneous nuclearribonucleoprotein L (HNRNPL) and muscleblind (MBL), could positively or negatively regulate the formation of circRNAs [32-35] (Fig. 1).

\section{Functional mechanisms of circRNAs \\ Act as miRNA sponges}

Multiple lines of evidence have proven that some circRNAs are rich in miRNA response elements (MREs) and may serve as miRNA sponges. MiRNAs are small, noncoding RNAs with approximately $22 \mathrm{nt}$ lengths that play an important role in posttranscriptional gene expression through binding to specific target sites within the mRNA 3'-untranslated region (3'-UTR), leading to decreased mRNA stability and suppression of translation [36, 37]. CircRNAs may regulate gene expression through binding to and releasing miRNAs from their downstream target genes [38, 39]. In comparison with other miRNA sponges, some circRNAs exhibit a superior ability to bind with miRNAs and have been referred to as "super sponge" [21]. The best example is CDR1as, which harbors more than 70 selectively conserved miR-7 binding sites [40]. In addition, there are a large number of examples of circRNAs able to act as miRNA sponges, including circRNA ZNF609 [41], circ-SRY [42], mm9_circ_012559 [43], circDOCK1 [44], and many others.

\section{Interact with RNA binding proteins}

In addition to acting as miRNA sponges, some circRNAs that harbor binding sites for RNA-binding proteins may serve as protein sponges or decoys and thus regulate gene expression. For instance, the circRNA originating from the PABPN1 locus (circ-PABPN1) binds to human 


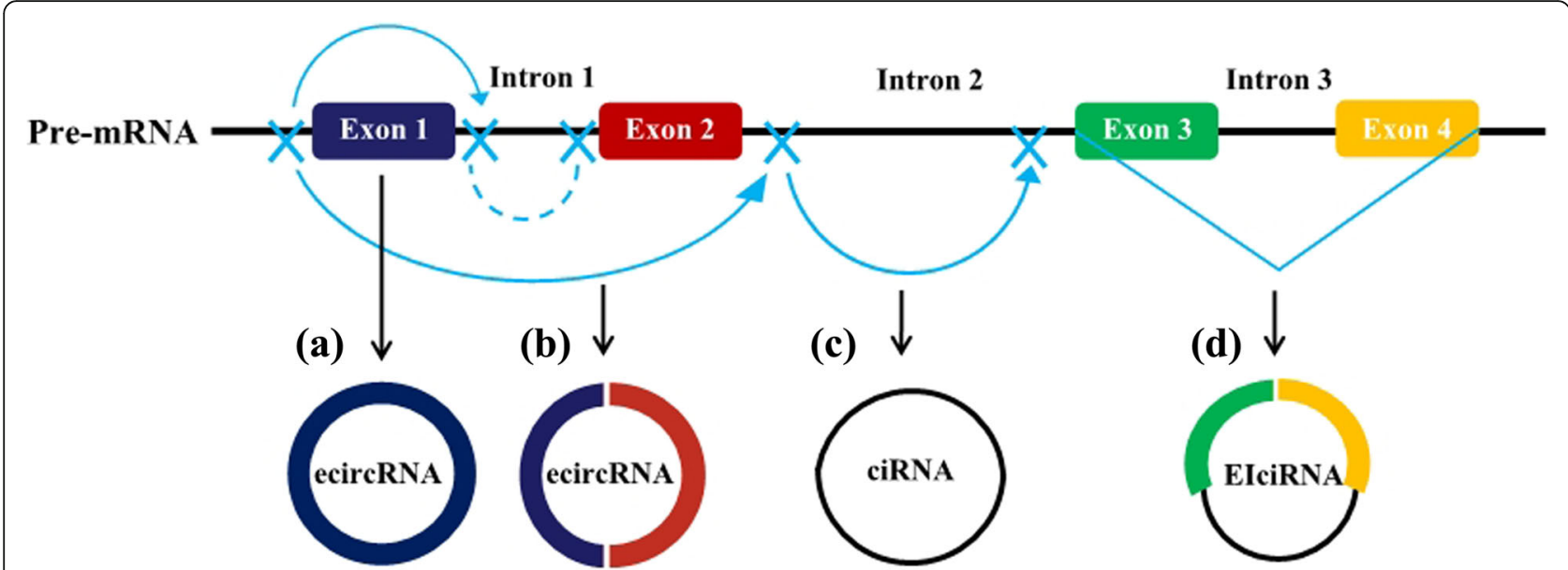

Fig. 1 Formation of three types of circRNAs. a Exonic circular RNA (ecircRNA) is formed through back-splicing of the $5^{\prime}$ splice site (splice donor site) to a 3'splice site (splice acceptor site); (b) The intron 1 is removed and bring the 5' splice site of Exon 2 close to 3' splice site of Exon 1, to form a ecircRNA that contains multiple exons. Exons can also skip splicing, exon 1 can also link with exon 3; (c) Circular intronic RNA (ciRNA) are derived from intron lariats that escape the normal intron debranching and degradation. Reverse complementary sequences of lariat intron excised from pre-mRNA can pair to produce close loop structure termed as ciRNA; (d) Exon-intron circRNAs (ElciRNAs) are circularized with introns'retained'between the exons. Intron 3 retaines with Exon 3 and Exon 4 to form an ElciRNAs

antigen R/ELAV-like protein 1 (HuR) and prevents HuR from binding to PABPN1 mRNA, subsequently suppressing PABPN1 translation [45]. The other examples, including circ-Foxo3 [46] and circ-Mbl [31], primarily interact with RNA binding proteins.

\section{Regulate transcription or splicing}

Some circRNAs have been demonstrated to regulate gene transcription through combining with RNA polymerase II complex and translating related proteins [47]. For example, circ-EIF3J and circ-PAIP2 were found to interact with the U1 snRNPs and RNA polymerase II in the promoter region of the host gene to realize enhanced transcription of their parental genes, such as PAIP2 and EIF3J [29].

Studies have also suggested that circRNAs can contribute to the regulation of selective splicing. A study by Ashwal-Fluss et al. [31] showed that circMbl is derived from the circularization of the second exon of the splicing factor muscleblind (MBL) and could compete with linear MBL mRNA for selective splicing. Notably, due to the presence of functional circMbl binding sites in the MBL protein, MBL could interact with circMbl and promote circMbl production. Thus, circMbl negatively affects canonical splicing and decreases the production of the parental mRNA.

\section{Translate proteins}

Because of lacking $5^{\prime}-3^{\prime}$ polarity and polyadenylated tails, as well as internal ribosome entry sites (IRES), circRNAs were initially defined as a distinct class of endogenous noncoding RNA that could not translate proteins [48, 49]. However, convincing evidence has shown that some circRNAs possess translational ability. To this point, at least four circRNA molecules have been proven to be translatable. Legnini I. et al. [50] revealed that circ-ZNF609 contains an open reading frame (ORF) and could be translated into a protein in murine myoblasts when driven by IRES. Additionally, circ-SHPRH [51] and circ-FBXW7 [52], as well as proteins encoded by them, are found to be abundantly expressed in normal human brains but downregulated in glioma. Both of the circRNAs have an ORF driven by the IRES to translate a functional protein. Analogously, Pamudurti N. R. et al. [53] found that circMbl can also translate protein in a cap-independent manner.

\section{Regulate epigenetic alterations}

Aberrant DNA methylation and histone modifications that associated with epigenetic gene expression are frequently found in cancer $[54,55]$. Some circRNAs have been found to regulate these epigenetic alterations. Chen et al. [56] reported that circFECR1 induced extensive CpG DNA demethylation in the promoter of FLI1 and thus epigenetically activated FLI1. CircFECR1 was demonstrated to downregulate the transcription of DNMT1, a critical methyltransferase required for the maintenance of DNA methylation, through binding to the DNMT1 promoter. In addition, circFECR1 could recruit TET1 DNA demethylase to the FLI1 promoter and induce DNA demethylation. Enhancer of zeste homolog 2 $(\mathrm{EZH} 2)$ is a subunit of polycomb-repressive complex 2 (PRC2), which functions as a H3K27 methyltransferase and regulates histone methylation $[57,58]$. Several circRNAs have been reported to regulate EZH2 expression 
through acting as miRNA sponges, subsequently regulate histone methylation indirectly. For example, circBCRC4 is able to promote the expression of EZH2 by binding with miR-101 [59], hsa_circ_0020123 is able to upregulate EZH2 and ZEB1 through sponging miR-144 [60], hsa_circ_0071589 can regulate the miR-600/EZH2 signaling [61] (Fig. 2).

\section{CircRNAs regulate the hallmarks of cancer}

In 2000, Hanahan and Weinberg proposed six hallmarks of cancer that result in the progressive conversion of normal cells into cancerous cells [62]. Most and perhaps all types of human cancer shared these acquired capabilities, including self-sufficiency in growth signals, evasion of antigrowth signals, resistance to cell death, limitless replicative potential, sustained angiogenesis, tissue invasion and metastasis. In recent years, some circRNAs have been shown to be involved in these properties of cancer (Fig. 3 and Table 1).

\section{Self-sufficiency in growth signals}

Normal cells acquire self-sufficiency in growth signals to change into an active proliferative state [62]. The mitogenic growth signals are transmitted into the cell interior by binding to the transmembrane receptors. Cancer cells could produce dysregulated growth factors and/or the corresponding receptor molecules themselves to lead to an autocrine stimulation.

Epidermal growth factor receptor (EGFR), highly expressed in a variety of solid tumors, is a critical molecular signal that can trigger an intracellular transduction cascade of growth factors and regulate cell growth $[63,64]$. A variety of studies have shown that EGFR is a target of miR-7, which is a tumor suppressor regulating various biological processes $[65,66]$. One of the most well-known circRNAs, CDRlas, harbors more than 70 selectively conserved miR-7 target sites, thus acting as a sponge of miR-7 [6, 7]. CDR1as, predominantly found in human brain, is approximately $1500 \mathrm{nt}$ in length [67]. CDR1as has been reported to be involved in pulmonary fibrosis, myocardial infarction, insulin secretion, neuropsychiatric disorders, and cancer [68-71]. Zhang et al. [72] reported that CDR1as was highly expressed in non-small cell lung cancer (NSCLC) tissues, correlated with TNM stage, lymph node metastasis and survival time, and acted as an independent prognostic factor for the NSCLC patients. Knockdown of CDR1as promotes cell vitality and growth through induction of cell apoptosis and cell cycle arrest in G1/S phase. Mechanical assays revealed that CDR1as functioned as a miR-7 sponge to increase the expression levels of miR-7 targeting proto-oncogenes (EGFR, CCNE1 and PIK3CD). In addition, CDR1as was also markedly overexpressed in colorectal cancer (CRC) tissues and correlated with advanced tumor stage, lymph node involvement, distant metastasis and poor patient survival of CRC patients [73]. Overexpression of CDR1as led to blocking of the tumor suppressive effects of miR-7 and resulted in a more aggressive oncogenic phenotype. Overexpression of CDR1as induced inhibition of miR-7 and subsequent activation of miR-7 target oncogenes EGFR and RAF1. However, in another study, CDR1as expression was shown to be downregulated in hepatocellular carcinoma (HCC) tissues and cell lines [74]. The expression

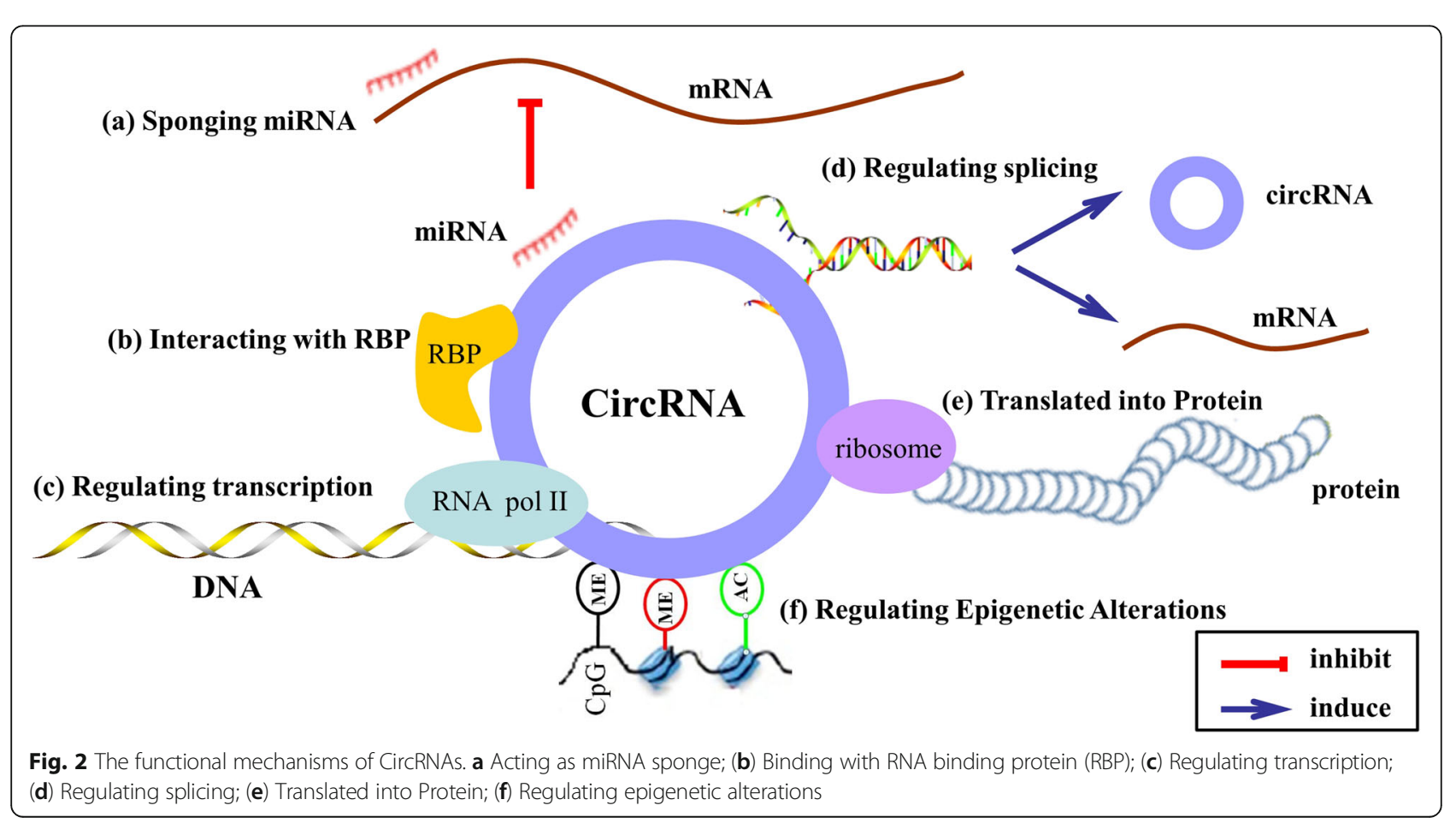




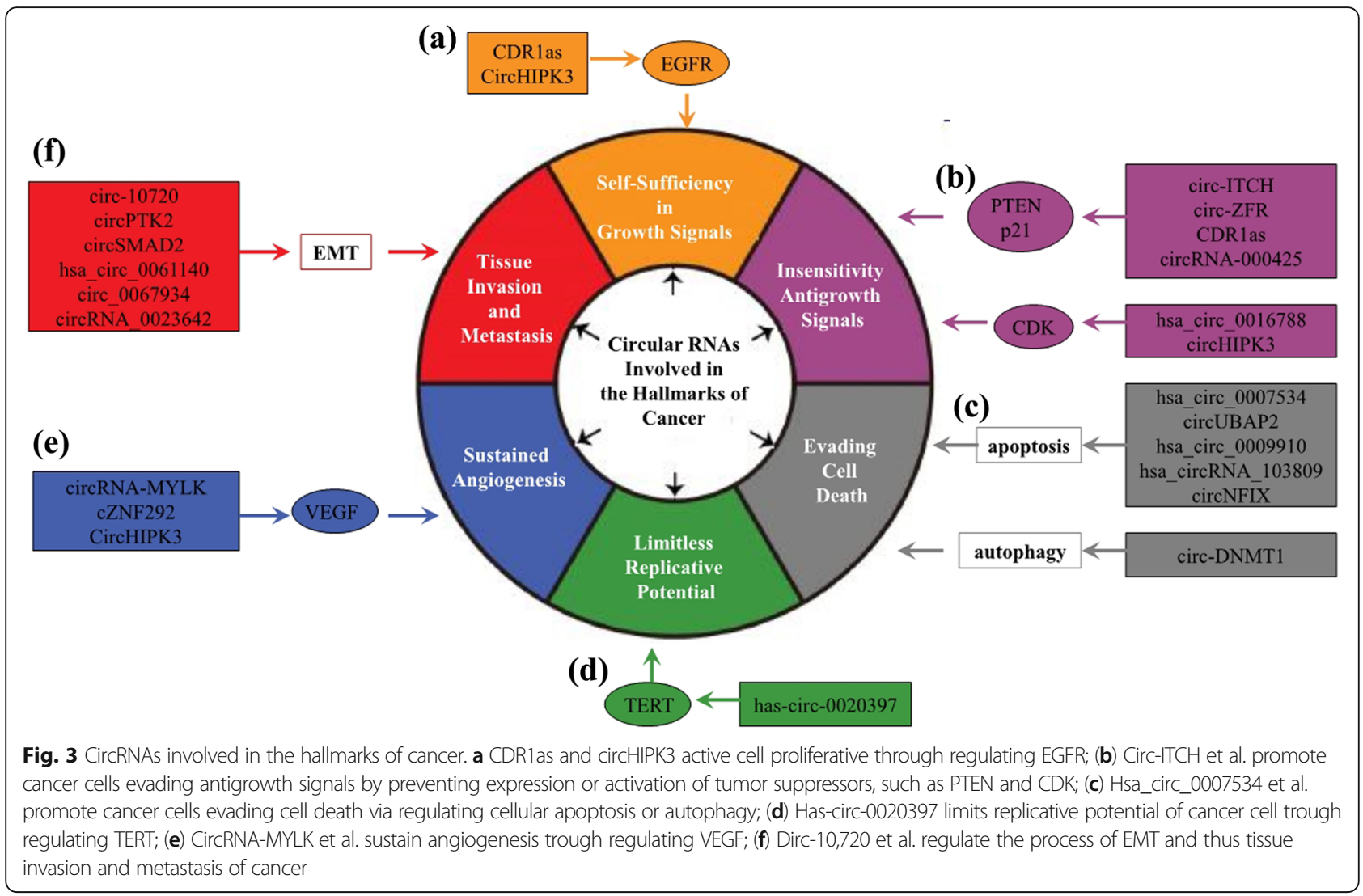

profiles differ between NSCLC, CRC and HCC, possibly due to the tissue-specificity of circRNAs. Ectopic expression of CDR1as could increase cell growth and adhesion while inhibiting the migration of HCC cells. CDRlas exhibited these functions through regulating the expression of EGFR. Another circRNA that regulates EGFR is circHIPK3 (hsa_circ_0000284), which originates from the HIPK3 gene exon 2 , with the length of $1099 \mathrm{nt}[75,76]$. CircHIPK3 is a particularly abundant circRNA that has been proposed to be involved in tumorigenesis [76, 77]. It was shown to be markedly overexpressed in CRC tissues and cell lines and positively associated with advanced clinical stage and poor survival of CRC patients [75]. CircHIPK3 knockdown significantly inhibited CRC cell proliferation while inducing cell apoptosis. Interestingly, miR-7 was identified and confirmed to be the only miRNA that directly interacts with circHIPK3 [75]. Furthermore, overexpression of circHIPK3 effectively reversed miR-7-induced attenuation of CRC cell progression through upregulating the expression of several key miR-7 target genes, including EGFR, IGF1R, FAK and YY1.

However, EGFR is not the only growth signal regulated by circRNAs. Integrins are transmembrane receptors and mediators of the interactions between cells and the extracellular matrix (ECM) [78]. Integrin-mediated interactions are required for the cytoskeletal organization, attachment, survival, proliferation, differentiation and migration of cells. Following binding to specific moieties of the ECM, the integrin receptors are able to transduce signals into the cell that mediate cell behavior. Integrin subunit beta 8 (ITGB8) is an important member of the integrin family [79]. A recently study showed that hsa_circ_0046701, which was highly expressed in glioma tissues and cell lines, was able to promote cell proliferation and invasion through regulating ITGB8 expression by sponging miR-142-3p [80].

C-myc, an important transcription factor, acts as an oncogene to regulate various cellular processes including cell proliferation, differentiation, and apoptosis [81, 82]. It has been reported that c-myc can regulate up to $15 \%$ of gene expression [83]. Yang and coworkers [52]conducted the RNA-expression profiling from glioblastoma and matched noncancerous tissues and characterized the circular form of the FBXW7 gene, circ-FBXW7. Circ-FBXW7 was downregulated in glioblastoma tissues and correlated with overall survival of glioblastoma patients. The spanning junction open reading frame in circ-FBXW7 driven by internal ribosome entry site encoded a novel 185 -amino acid protein, which was termed as FBXW7-185aa. FBXW7-185aa, but not circ-FBXW7, could function as a tumor suppressor to induce cell cycle arrest and inhibit proliferation in glioma cells through reducing the half-life of c-myc. FBXW7-185aa was shown to directly interact with de-ubiquitinating enzyme 


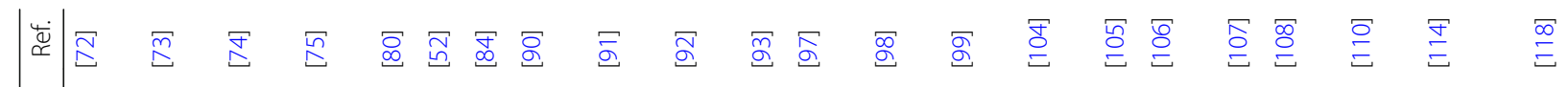

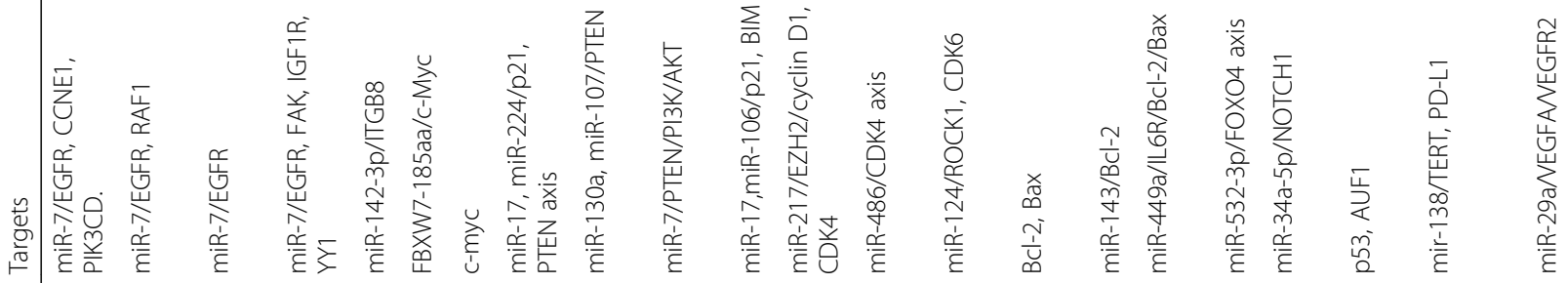
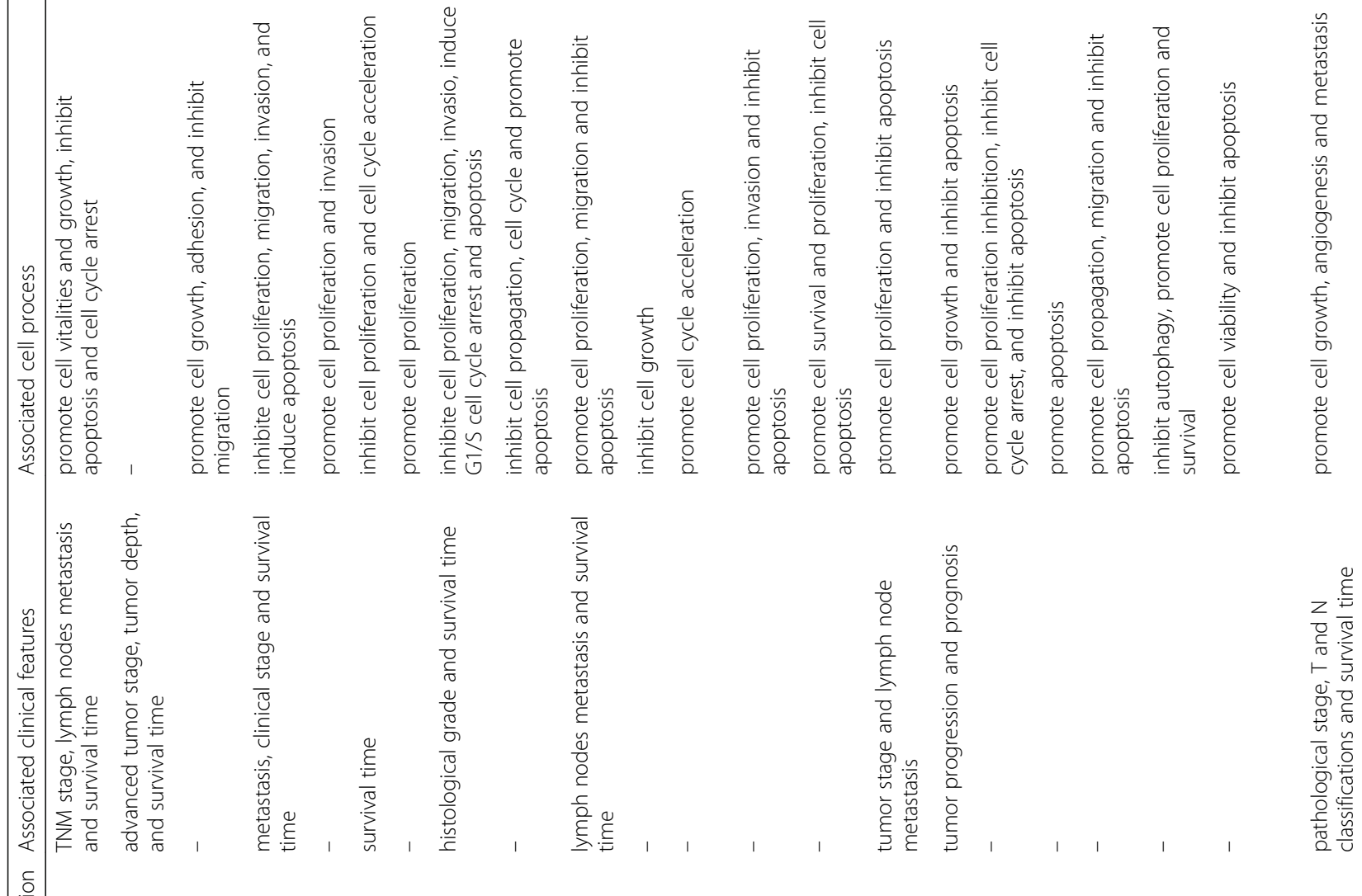

离恼

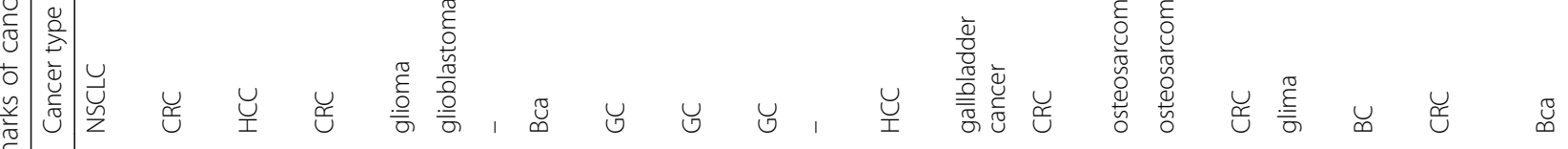

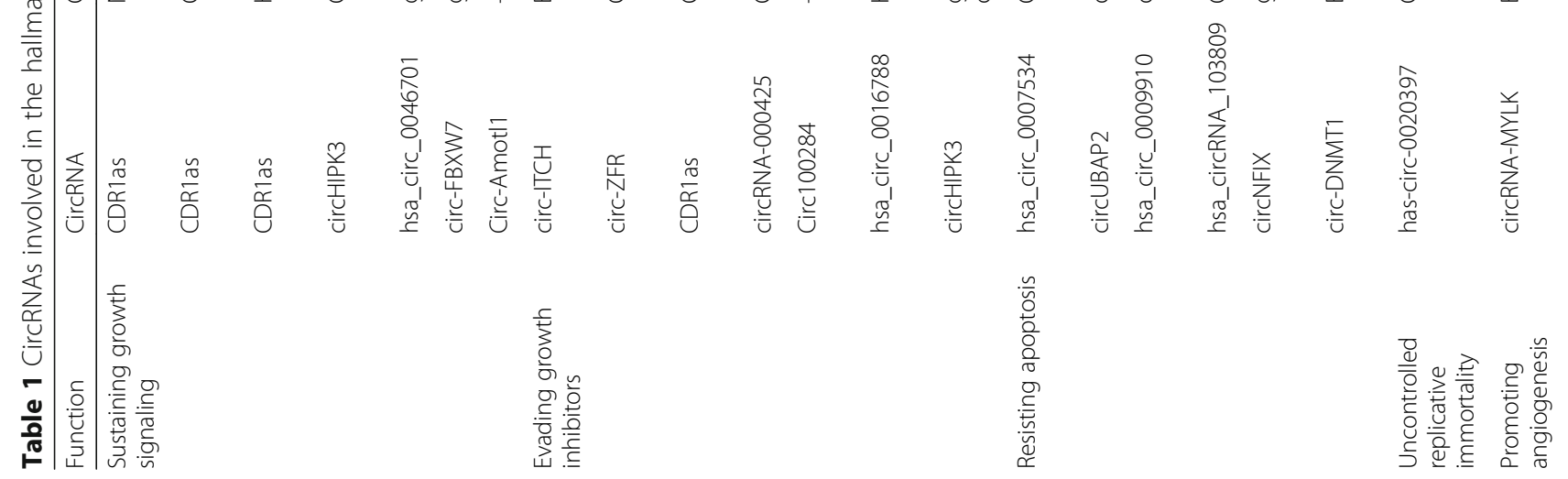




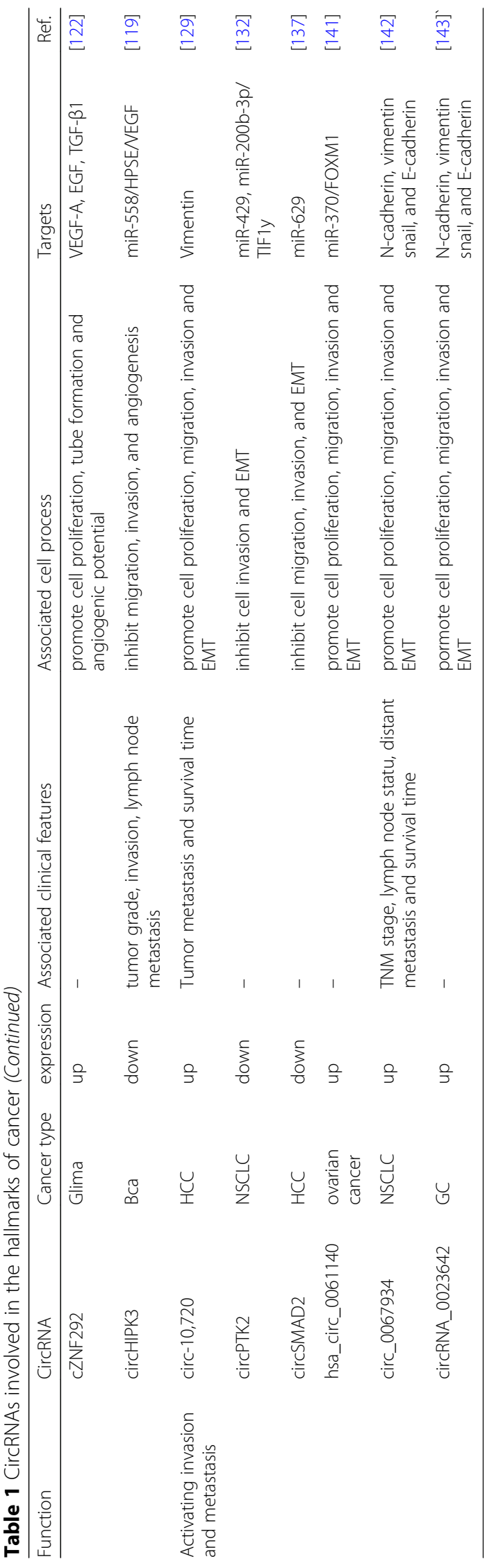


USP28, and thus antagonize the USP28-induced de-ubiquitination of c-Myc and increase c-Myc ubiquitination. Another circRNA that could regulate c-myc is circRNA derived from angiomotin-like1 (circ-Amotl1) [84]. Circ-Amotl1 was highly expressed in breast cancer (BC) tissues and cell lines. Knockdown of circ-Amotl1 promoted cell proliferation and inhibited apoptosis of $\mathrm{BC}$ cells. In addition, circ-Amotll was demonstrated to bind to c-myc, translocate into nucleus and prevented degradation of c-myc. Ectopic expression of circ-Amotl1 enhanced the binding affinity of c-myc to the promoters of a number of its targets, including HIF- $1 \alpha$, Cdc25a, ELK-1, and JUN. However, how circ-Amotl1 prevents c-myc degradation is not clear and awaits further investigation.

\section{Insensitivity antigrowth signals}

There are multiple antiproliferative signals in normal cells that operate to maintain cells in a quiescent state [62]. These signals can block cell proliferation through arresting the cell cycle [85]. However, cancer cells can evade antigrowth signals by preventing expression or activation of tumor suppressors.

Phosphatase and tensin homolog (PTEN), deleted from chromosome ten and mutated at high frequency in a variety of cancers, can contribute to the G0-G1 cell cycle regulation and additional cellular functional activities [86, 87]. Cyclin-dependent kinase (CDK) inhibitor p21 is a cell cycle suppressing protein, and overexpression of p21 acts to suppress cell growth [88, 89]. Circ-ITCH, the circularized product from several exons of itchy E3 ubiquitin protein ligase homolog (ITCH), has been reported to be downregulated in bladder cancer (BCa)tissues and correlated with the histological grade and shortened survival of $\mathrm{BCa}$ patients [90]. It was also downregulated in $\mathrm{BCa}$ cell lines, and the enforced expression of circ-ITCH inhibited cell proliferation, migration, invasion and metastasis. Mechanical assays demonstrated that circ-ITCH could directly sponge miR-17 and miR-224 and lead to increased expression of their target genes, PTEN and p21. Another circRNA, circ-ZFR, was shown to be downregulated in gastric cancer (GC); circ-ZFR regulated GC progression by directly binding with miR-130a/ miR-107, and further regulated the expression of PTEN, which is a target of these miRNAs [91]. In addition, CDR1as was overexpressed in GC tissues and correlated with poor survival [92]. Ectopic expression of CDR1as increased expression of PTEN through sponging of miR-7 and subsequently activated the PTEN/PI3K/AKT pathway. Liu and colleagues [93] identified circRNA-000425 as a novel inhibitory target of Yes-associated protein 1 (YAP1), an transcriptional coactivator factor that acts as an oncogene associated with cancer malignancy in several cancer types [94, 95]. YAP1 could suppress the expression of circRNA-000425 through binding to the promoter of
HNRNPH1, which codes for circRNA-000425. CircRNA-000425 was identified as a sponge of miR-17/ miR-106b and indirectly modulated their targets, such as p21 and BIM, thus suppressing GC cell growth.

In addition to these well-known tumor suppressors, some circRNAs could also regulate tumor growth by regulating cell cycle mediators, such as Cyclin D1, a well-known regulator of the cell cycle that promotes the transition from $\mathrm{G} 1$ to $\mathrm{S}$ phase by activating CDK4 or CDK6 [96]. Xue and coworkers [97] performed a circRNA microarray to analyze the variability of circRNAs in arsenite-treated $\mathrm{HaCaT}$ (As-HaCaT) cells and in arsenite-transformed cells compared to normal $\mathrm{HaCaT}$ cells and identify cirRNAs that involved in arsenite-induced acceleration of the cell cycle. Circ100284 was greatest up-regulated in As-HaCaT cells and showed the most change following arsenite treatment. Knockdown of circ100284 inhibited G1/S transition in As-HaCaT cells. Circ100284 was demonstrated to be involved in the arsenite-promoted cell cycle through regulation of EZH2 via sponging miR-217. EZH2 subsequently bind to the promoter of CCND1, the host gene of cyclin D1. Knockdown of EZH2 suppressed the expression of cyclin D1 and CDK4. Although EZH2 frequently acts through methylation of H3K27 as discussed above, here, it functions through the methylase-independent pathway. These results suggested that, in $\mathrm{HaCaT}$ cells, circ100284 was induced by arsenite treatment and acted as a sponge for miR-217 to up-regulate EZH2, which, in turn, increased the expression of cyclin D1 and CDK4, and thus lead to cell cycle acceleration and malignant transformation. In another study, Guan et al. [98] performed circRNA microarray analysis in HCC tissue and identified a highly expressed circRNA, hsa_circ_0016788. Silencing of hsa_circ_0016788 inhibited proliferation and promoted apoptosis of HCC cells through regulation of the miR-486/CDK4 axis. CircHIPK3 was shown to be overexpressed in human gallbladder cancer cells [99]. Silencing of circHIPK3 decreased the proliferative and survival capacities, induced apoptosis of gallbladder cancer cells through sponging the tumor-suppressive miR-124, and increased expression of ROCK1 and CDK6, which are miR-124 targets $[100,101]$.

\section{Evading apoptosis}

Apart from the rate of cell proliferation, the rate of cell attrition also determines the populations of cells [62]. Apoptosis is the major mechanism leading to this attrition. The other two pathways related to cell attrition are autophagy and necrosis [85]. Cancer cells acquired the ability to evade these signals.

It is well known that B-cell lymphoma-2 (Bcl-2) is an important anti-apoptotic molecule that protects cells from apoptosis, while BCL2-associated X protein (Bax) is a proapoptotic gene $[59,102]$. Thus, the ratio of 
$\mathrm{Bcl}-2 / \mathrm{Bax}$ is a profound indicator of cell survival [103]. Hsa_circ_0007534 was significantly overexpressed in CRC tissues and related to tumor stage and lymph node metastasis [104]. Silencing of hsa_circ_0007534 inhibited proliferation while promoting the apoptosis of CRC cells. Moreover, the $\mathrm{Bcl}-2 / \mathrm{Bax}$ ratio was decreased following hsa_circ_0007534 silencing, which demonstrated that hsa_circ_0007534 inhibits CRC cell proliferation, at least partially, by inducing apoptosis. However, how hsa_circ_0007534 regulates the Bcl-2/Bax ratio is so far unknown and further studies will need to unravel the molecular mechanism.

Zhang et al. [105] performed microarray experiments to examine the expression profiles of circRNAs in osteosarcoma tissue and found that circUBAP2 was the most markedly increased circRNA. CircUBAP2 was also significantly overexpressed in osteosarcoma cells. CircUBAP2 knockdown inhibited cell proliferation and promoted cell apoptosis. Mechanistically, circUBAP2 was found to directly bind to and inhibit the expression of miR-143, thus enhancing the expression of the miR-143 target Bcl-2. Another study performed by Deng et al. [106] showed that hsa_circ_0009910 was upregulated in osteosarcoma cells. Circ_0009910 knockdown inhibited cell proliferation and induced cell cycle arrest and apoptosis in osteosarcoma cells. Circ_0009910 was found to directly bind to and function as a sponge of miR-449a, thereby regulating the target gene IL6R as well as the downstream Bcl-2 and Bax.

In addition, there are several additional circRNAs involved in apoptosis. For example, Hsa_circRNA_103809 was downregulated in CRC and could promote apoptosis through the miR-532-3p/FOXO4 axis [107]. CircNFIX was overexpressed in glioma and inhibited apoptosis through regulating NOTCH1 via binding to and sponging miR-34a-5p [108].

Apart from apoptotic roles, there is also a circRNA involved in autophagy. It has been reported that nuclear translocation of p53 could induce cellular autophagy [109]. Circ-Dnmt1, generated from Exons 6 and 7 of the mRNA NM_001130823.1, was found to be upregulated in tissues of $\mathrm{BC}$ as well as in eight $\mathrm{BC}$ cell lines [110]. Overexpression of circ-Dnmt1 increased cell survival and proliferation of $\mathrm{BC}$ cells through stimulating cellular autophagy. In addition, nuclear levels of circ-Dnmt1 were increased in autophagy inducer-treated BC cells, indicating that autophagy could enhance the nuclear translocation of circ-Dnmt1. Circ-Dnmt1 could directly bind with p53, promoting its nuclear translocation.

\section{Limitless replicative potential}

Replicative potential is limited because of the appearance of two processes termed as senescence or crisis in normal cells [62]. The telomeres that locate at the chromosome ends are critical for this finite replicative potential: they shorten after every cell division, and therefore, the number of cell division cycles is dictated by the length of telomeres [111]. Approximately $85-90 \%$ of human cancers overexpress telomerase, which adds telomeric repeats onto the ends of telomeric DNA, suggesting that limitless replicative potential is essential for the development of their malignant growth [112].

Telomerase reverse transcriptase (TERT) is a catalytic subunit of telomerase [113]. Zhang and colleagues [114] reported that hsa_circ_0020397, derived from the DOCK1 gene, was upregulated in CRC cells, promoted their viability, and inhibited apoptosis. By using a common bioinformatic algorithm, the authors predict that an important cancer suppressor, miR-138, possesses multiple binding sites on hsa_circ_0020397. In addition, has_circ_0020397 was demonstrated to inhibit the activity of miR-138, although it did not influence miR-138 expression, and increase the expression of miR-138 target genes including PD-L1 and TERT.

\section{Sustained angiogenesis}

Tumor size increases when cancer cells grow. However, the size is limited to within $100-200 \mu \mathrm{m}$ without angiogenesis due to the limited natural diffusion capability of oxygen and nutrients [115]. Angiogenesis is the process induced by tumor cells that forms new blood vessels in order to supply the tumor with oxygen and nutrients and to dispose of tumor metabolic (toxic) wastes.

Vascular endothelial growth factor (VEGF) is believed to be the most potent mediator of crucial regulatory roles in angiogenesis [116, 117]. CircRNA-MYLK is spliced from MYLK gene, with the spliced mature sequence length of $376 \mathrm{nt}$ [118]. It was significantly overexpressed in $\mathrm{BC}$ tissues and correlated with the clinical features of $\mathrm{BC}$ patients including the pathological stage, $\mathrm{T}$ and $\mathrm{N}$ classifications, and survival time. CircRNA-MYLK was also upregulated in $\mathrm{BC}$ cell lines. Moreover, circRNA-MYLK promoted cell proliferation, migration, and the tube formation of HUVECs, which exhibits angiogenic potential. Mechanistically, circRNA-MYLK could directly bind to and sponge miR-29a, thus relieving suppression for target VEGFA and activating the VEGFA/ VEGFR2 signaling pathway. CircRNA-MYLK is not the only circRNA that plays a critical role in tumor angiogenesis: another circRNA, circHIPK3 [119], was shown to be downregulated in Bca and suppress angiogenesis through the sponging of miR-558 and subsequent inhibition of HPSE, which could positively regulate the expression of VEGF [120, 121]. cZNF292 was also reported to be an important circular oncogenic RNA taking part in the progression of tube formation in glioma [122]. The expression of VEGF-A, EGF and active TGF- $\beta 1$, as well as the levels of VEGFR-1/2, phosphorylated-VEGFR-1/2 and EGFR, 
were significantly downregulated following the silencing of cZNF292. Since the in-depth mechanism of cZNF292 activity is unclear, more studies are necessary.

\section{Tissue invasion and metastasis}

It is believed that $90 \%$ of human cancer deaths are caused by metastases and not by the primary tumor [123]. During the development of most types of human cancer, cancer cells can escape the primary tumor mass and initiate new colonies at distant sites. The process of epithelial-mesenchymal transition (EMT) has been confirmed to be essential in cell migration and tissue metastasis in cancer $[124,125]$. It involves a cellular reprogramming process that drives epithelial cells into a mesenchymal-like phenotype, which is characterized by the loss of epithelial surface markers like E-cadherin and the acquisition of the mesenchymal markers vimentin and N-cadherin.

The Twist family is known as critical EMT-inducing transcription factor that increase expression of vimentin [126-128]. Meng et al. [129] demonstrated that twist1 bound to the promoter of $\mathrm{Cul} 2$ to activate its transcription and selectively induce expression of $\mathrm{Cul} 2$ circular RNA (circ-10,720) rather than mRNA. Circ-10,720 expression was high in metastatic HCC tissues and associated with clinical stage, pathology grade, metastasis and survival of patients. Circ-10,720 played an oncogenic role to promote the migration, invasion and EMT progression of HCC cells. Furthermore, it was found that twist1 promoted vimentin through increasing levels of circ-10,720, which could sponge miRNAs targeting Vimentin, including miR-1246, miR-578 and miR-490-5p. Among them, miR-490-5p was considered to be the major miRNA regulating Vimentin in HCC due to its high expression and stronger inhibitory effects to Vimentin 3'-UTR activities.

TGF- $\beta$ /Smad signaling has been proven to play a crucial role in tumor metastasis and the EMT process in a variety of human cancers [130, 131]. CircPTK2 (hsa_circ_0008305) was found to be markedly downregulated in NSCLC cells during TGF- $\beta$-induced EMT [132]. Overexpression of circPTK2 arrested TGF- $\beta$-induced EMT and invasion of NSCLC cells. Mechanistically, circPTK2 functions as a sponge of miR-429/miR-200b-3p, which promotes EMT and cell invasion through targeting TIF1 $\gamma$. TIF1 $\gamma$ is a TGF- $\beta /$ Smad signaling regulator that could escalate TGF- $\beta$-induced EMT in cancer [133, 134]. In addition, circPTK2 could also negatively regulate the expression of Snail, an important downstream regulator of TGF- $\beta /$ Smad signaling [135].

Compelling data revealed that SMAD2 potently contributes to EMT [136]. Zhang et al. [137] reported that circSMAD2 (hsa_circ_0000847), encoded by the SMAD2 gene, was upregulated during TGF- $\beta$-induced EMT. In addition, the expression of circSMAD2 was downregulated in HCC tissues and correlated with the tumor differentiation degree. Overexpression of circSMAD2 inhibited migration, invasion, and EMT in HCC cells through suppressing the expression of miR-629, which could promote EMT in cancer cell lines.

FOXM1 has been shown to promote cell migration, invasion and EMT in a variety of tumors [138-140]. Chen et al. [141] reported that hsa_circ_0061140 was overexpressed in ovarian cancerand could promote cell migration and invasion through regulation of the miR-370/FOXM1 pathway-mediated EMT. Hsa_circ_0061140 silencing induced a decreased expression of the EMT-related proteins, Snail and Vimentin, along with an increased expression of E-cadherin.

Circ_0067934 was shown to be upregulated in NSCLC and capable of promoting cell EMT accompained with increased $\mathrm{N}$-cadherin and vimentin expression and decreased E-cadherin expression [142]. CircRNA_0023642 was upregulated in GC and acted as an oncogene by regulating EMT [143]. CircRNA_0023642 was shown to suppress expression of E-cadherin and promote expression of N-cadherin, vimentin, and snail in GC cells. Since the studies didn't show the effector molecules of circ_0067934 and circRNA_0023642, the exact mechanisms of the two circRNAs still need to be uncovered.

In addition to the circRNAs discussed above, it is likely that many more circRNAs could regulate the hallmarks of cancer as a large number of studies have shown that circRNAs are involved in modulating proliferation, apoptosis and migration of cancer cells without exploring the underling molecular mechanisms.

\section{CircRNAs regulate stemness of cancer}

Cancer stem cells (CSCs), a small proportion of cells that possess self-renewal and tumor-initiating capabilities, are considered to be responsible for metastatic dissemination and therapeutic failure [144-146]. Several lines of evidence have suggested that circRNAs might contribute to the stemness of cancer (Table 2).

Yang and colleagues [147] performed high-throughput sequencing to screen the circRNA expression profiles of breast CSCs (BCSCs) and matched non-BCSCs and found 27 aberrantly expressed circRNAs. Among these, circVRK1 was downregulated and was able to suppress the expansion and self-renewal capacity of BCSCs, displaying an inhibiting role in the stemness of BCSCs. BC cells with circVRK1 knockdown exhibited an enhanced capacity to form mammospheres and colonies, and an increasing expression of stemness-related markers including OCT4, SOX2 and NANOG, indicating that circVRK1 was involved in suppressing the stemness of BCSCs. In addition, it was speculated that circVRK1 was negatively correlated with stemness of BCSCs through 
Table 2 CircRNAs involved in stemness and chemotherapy resistance of cancer

\begin{tabular}{|c|c|c|c|c|c|c|c|}
\hline Function & CircRNA & Cancer type & expression & Associated clinical features & Associated cell process & Targets & Ref \\
\hline \multirow[t]{2}{*}{$\begin{array}{l}\text { Regulating } \\
\text { stemness }\end{array}$} & circVRK1 & $B C$ & down & - & $\begin{array}{l}\text { decrease proportion of BCSCs } \\
\text { with CD44 + CD24- phenotype, } \\
\text { suppress BCSC's expansion and } \\
\text { self-renewal capacity }\end{array}$ & - & [147] \\
\hline & hg19_circ_0005033 & LSCC & up & - & $\begin{array}{l}\text { promote proliferation, migration, } \\
\text { invasion, and chemotherapy } \\
\text { resistance of laryngeal cancer } \\
\text { stem cells }\end{array}$ & miR-4521 & [150] \\
\hline \multirow[t]{3}{*}{$\begin{array}{l}\text { Regulating } \\
\text { chemotherapy } \\
\text { resistance }\end{array}$} & circPVT1 & osteosarcoma & up & $\begin{array}{l}\text { enneking stage, } \\
\text { chemoresistance, lung } \\
\text { metastasis and survival }\end{array}$ & $\begin{array}{l}\text { contributes to doxorubicin } \\
\text { and cisplatinresistance }\end{array}$ & $A B C B 1$ & [154] \\
\hline & $\begin{array}{l}\text { circRNA-MTO1 } \\
\text { (hsa-circRNA- } \\
\text { 007874) }\end{array}$ & $\mathrm{BC}$ & up & - & $\begin{array}{l}\text { inhibit cell viability and } \\
\text { reverse monastrol resistance }\end{array}$ & $\begin{array}{l}\text { TRAF4/Eg5 } \\
\text { axis }\end{array}$ & [157] \\
\hline & $\operatorname{circBA9.3}$ & CML & up & - & $\begin{array}{l}\text { promote resistance against } \\
\text { TKI therapy }\end{array}$ & $\begin{array}{l}\text { C-ABL1 and } \\
\text { BCR-ABL1 }\end{array}$ & [159] \\
\hline
\end{tabular}

the miR-153-5p/KLF5 axis, as miR-153-5p was one of the predicted miRNA targets of circVRK1 and was previously demonstrated to be involved in stemness maintenance of $\mathrm{BC}$ via reducing the expression of KLF5 [148]. Further investigations are necessary to support the hypothesis.

CD133 + CD44+ CSCs (TDP cells), isolated from laryngeal squamous cell carcinoma (LSCC) cells, have been shown to exhibit increased cell proliferation, migration and colony-formation ability as well as resistance to chemo- and radiotherapy [149]. These TDP cells were shown to highly express the stem-cell markers SOX2 and OCT4. In comparison with parental cells, TDP cells exhibited 3684 circRNAs by RNA sequencing $(\mathrm{q}<0.01$ and $\log 2 \mathrm{FC}$ (fold change) > 1) [150]. Hg19_circ_0005033 was one of the upregulated circRNAs in TDP cells, and it could promote the proliferation, migration, invasion, and resistance to chemotherapy of TDP cells. Hg19_circ_0005033 was demonstrated to bind to miR-4521 and could function as ceRNA to upregulate miR-4521 targeted mRNAs. In addition, STAT5A, which was previously reported to induce stem-like cell properties [151], was predicted as a target of miR-4521. Thus, hg19_circ_0005033 was hypothesized to support the stem cell characteristics of CD133+CD44+ LSCC stem cells via the miR-4521/STAT5A axis, which need further validation.

\section{CircRNAs regulate chemotherapy resistance of cancer}

Chemotherapy represents the primary treatment for both early and advanced tumors. However, acquired resistance to chemotherapy is one of the major causes of therapeutic failure [130]. Recently, several circRNAs have been proven likely to play vital roles in the resistance of cancer to chemotherapy (Table 2).

It is well known that ATP-binding cassette B1 $(\mathrm{ABCB} 1)$ is a multidrug resistance-related protein that is highly expressed in drug resistant cell lines and could promote resistance to chemotherapy through pumping intracellular drugs outside of the cell [152, 153]. CircPVT1 (hsa_circ_0001821), originating from exon 3 of the PVT1 gene, was significantly overexpressed in OS tissues and associated with poor prognosis of OS patients [154]. It was also upregulated in chemoresistant OS cell lines, and circPVT1 knockdown could weaken the doxorubicin and cisplatin resistance of OS cells via suppressing the expression of ABCB1.

Monastrol is a small molecule that selectively inhibits Eg5, a microtubule-based motor protein that contributes to the formation and maintenance of the bipolar mitotic spindle [155, 156]. Liu et al. [157] performed a genome-wide circRNA microarray to search for dysregulated circRNAs in the monastrol-resistant BC cells and identified circRNA-MTO1 (has-circRNA-007874) as an upregulated circRNA in these cells. Upregulation of circRNA-MTO1 promoted monastrol-induced cell cytotoxicity and reversed monastrol resistance. Mechanistically, circRNA-MTO1 could suppress expression of Eg5 through binding with TRAF4 and serve as a competing endogenous RNA (ceRNA) to repress TRAF4 from binding to the Eg5 gene.

Tyrosine kinase inhibitors (TKIs) are available for managing chronic myelogenous leukaemia (CML) [158]. Pan and colleagues [159] identified an f-circRNA, circBA9.3, generated from the BCR-ABL1 oncoprotein, that could contribute to the increased proliferation and anti-apoptotic capacities of leukaemic cells [160]. CircBA9.3 was upregulated in patients with TKI resistance and could enhance the expression of BCR-ABL1, thus contributing to resistance against TKI therapy.

\section{CircRNAs as biomarkers in Cancer}

The properties of circRNAs mentioned in previous sections (stability, conservatism, universality, and specificity) 
indicate that circRNAs could be potentially valuable prognostic and diagnostic biomarkers for cancer. Recently, many studies have demonstrated circRNAs may be stably expressed and present in relatively high quantities in human body fluids, such as saliva, plasma, serum and exosomes, which also makes circRNAs ideal candidates as noninvasive liquid biopsy biomarkers for cancer [161]. Circ-ZEB1.33 was shown to be overexpressed in human HCC tissues compared to non-tumorous tissues and in serum samples from HCC patients compared to healthy controls, and its levels in HCC tissue and serum were correlated with different TNM stages and overall survival in HCC patients, suggesting circ-ZEB1.33 may serve as a valuable biomarker in HCC prognosis prediction [162]. Hsa_circ_0000190 was down-regulated in GC tissues and plasma samples [163]. Its expression levels were significantly associated with tumor size, distal metastasis, lymphatic metastasis, TNM stage and CA19-9 levels. The area under curve (AUC) of hsa_circ_0000190 in tissues and plasma were 0.75 and 0.60 , respectively; the AUC of the combination was increased to 0.775 , and the sensitivity and specificity of the combination were 0.712 and 0.750, respectively. In another study, hsa_circ_0000745 was shown to be lowly expressed in GC tissues and plasma samples [164]. The expression level of hsa_circ_0000745 in GC tissues was correlated with tumor differentiation, while the expression level in plasma was correlated with tumor-node metastasis stage. The AUC of hsa_circ_0000745 in plasma was 0.683 , while combined with carcinoembryogenic antigen (CEA) level, the AUC

Table 3 CircRNAs as liquid biopsy biomarkers in cancer

\begin{tabular}{|c|c|c|c|c|c|c|}
\hline Source & $\begin{array}{l}\text { Cancer } \\
\text { type }\end{array}$ & Cohort size & CircRNA & Expression & Associated clinical features & Ref \\
\hline \multirow[t]{2}{*}{ saliva } & OSCC & $\begin{array}{l}90 \text { OSCC patients, } 70 \\
\text { OLK subjects }\end{array}$ & hsa_circ_0001874 & up & TNM stage, tumor grade & {$[165]$} \\
\hline & oscC & $\begin{array}{l}90 \text { OSCC patients, } 70 \\
\text { OLK subjects }\end{array}$ & hsa_circ_0001971 & up & TNM stage & [165] \\
\hline \multirow[t]{11}{*}{ plasma } & GC & $\begin{array}{l}104 \text { GC patients, } 104 \\
\text { healthy individuals }\end{array}$ & Hsa_circ_0000190 & down & $\begin{array}{l}\text { tumor diameter, lymphatic metastasis, distal } \\
\text { metastasis, TNM stage, CA19-9levels }\end{array}$ & [163] \\
\hline & GC & $\begin{array}{l}20 \text { GC patients, } 20 \\
\text { healthy individuals }\end{array}$ & hsa_circ_0006633 & up & $\begin{array}{l}\text { distal metastasis, tissue carcinoembryonic antigen } \\
\text { level }\end{array}$ & [167] \\
\hline & GC & $\begin{array}{l}45 \mathrm{GC} \text { patients, } 17 \\
\text { healthy individuals }\end{array}$ & hsa_circ_0000520 & down & CEA expression & [168] \\
\hline & GC & $\begin{array}{l}24 \text { GC patients, } 14 \\
\text { healthy individuals }\end{array}$ & hsa_circ_0000673 & down & TNM stage & [169] \\
\hline & GC & $\begin{array}{l}121 \text { GC patients, } 121 \\
\text { healthy individuals }\end{array}$ & $\begin{array}{l}\text { hsa_circ_0001017, } \\
\text { hsa_circ_0061276 }\end{array}$ & down & OS, DFS & [170] \\
\hline & ESCC & $\begin{array}{l}30 \text { ESCC patients, } 25 \\
\text { healthy individuals }\end{array}$ & Circ-TTC17 & up & TNM stage, lymphatic metastasis, OS & [171] \\
\hline & PC & $\begin{array}{l}31 \text { PC patients, } 31 \\
\text { healthy individuals }\end{array}$ & circ-LDLRAD3 & up & $\begin{array}{l}\text { CA19-9, N classification, venous invasion, } \\
\text { lymphatic invasion }\end{array}$ & [172] \\
\hline & $\mathrm{BC}$ & $\begin{array}{l}57 \mathrm{BC} \text { patients, } 17 \\
\text { healthy individuals }\end{array}$ & hsa_circ_0001785 & down & histological grade, TNM stage, distant metastasis & [173] \\
\hline & $\mathrm{HCC}$ & $\begin{array}{l}104 \text { HCC patients, } 52 \\
\text { healthy individuals }\end{array}$ & hsa_circ_0001445 & down & AFP level & [174] \\
\hline & GC & $\begin{array}{l}102 \mathrm{GC} \text { patients, } 105 \\
\text { healthy individuals }\end{array}$ & Hsa_circ_0000181 & down & tumor differentiation, carcinoembryonic antigen & [175] \\
\hline & LAC & $\begin{array}{l}30 \text { LAC patients, } 30 \\
\text { healthy individuals }\end{array}$ & hsa_circ_0013958 & up & TNM stage, lymphatic metastasis & [176] \\
\hline \multirow[t]{3}{*}{ serum } & $\mathrm{HCC}$ & $\begin{array}{l}64 \text { HCC patients, } 30 \\
\text { healthy individuals }\end{array}$ & circ-ZEB1.33 & up & TMN stages, OS & [162] \\
\hline & $\mathrm{BCa}$ & $\begin{array}{l}197 \text { BCa patients, } 97 \\
\text { healthy individuals }\end{array}$ & hsa_circ_0000285 & down & $\begin{array}{l}\text { tumor size, differentiation, lymph node metastasis, } \\
\text { distant metastasis, TNM stage, OS }\end{array}$ & [177] \\
\hline & NPC & $\begin{array}{l}150 \text { NPC patients, } 100 \\
\text { healthy individuals }\end{array}$ & circRNA_0000285 & up & $\begin{array}{l}\text { tumor size, differentiation, lymph node metastasis, } \\
\text { distant metastasis, TNM stage. }\end{array}$ & [178] \\
\hline \multirow[t]{2}{*}{$\begin{array}{l}\text { exosome } \\
\text { (serum and urine) }\end{array}$} & UCB & $\begin{array}{l}71 \text { UCB patients, } 36 \\
\text { healthy individuals }\end{array}$ & circPRMT5 & up & lymph node metastasis, $T$ and N status, DFS & [166] \\
\hline & UCB & $\begin{array}{l}18 \text { UCB patients, } 14 \\
\text { healthy individuals }\end{array}$ & circPRMT5 & up & lymph node metastasis, T and N status, DFS & [166] \\
\hline
\end{tabular}


increased to 0.775 , suggesting good diagnostic value of hsa_circ_0000745 in plasma in combination with CEA level in GC. Zhao and colleagues [165] performed microarray screening of circRNA in saliva from oral squamous cell carcinoma patients compared with healthy controls and identified 20 downregulated and 12 upregulated circRNAs in oral squamous cell carcinoma saliva. Among these, two upregulated circRNAs, hsa_circ_0001874 and hsa_circ_0001971, showed a AUC of 0.863 and 0.845, respectively. The combination of these two circRNAs showed a AUC of 0.922. Furthermore, the risk score based on hsa_circ_0001874 and hsa_circ_0001971 could discriminate patients with OSCC from patients with oral leukoplakia with AUC for risk score 0.863, suggesting potential of salivary hsa_circ_0001874 and hsa_circ_0001971 as OSCC diagnostic biomarker. Moreover, recently studies have found that circRNAs were enriched and stable in exosomes, which are small membrane vesicles secreted by tumor cells into the extracellular fluids. Chen and colleagues [166] revealed that circPRMT5 was enriched in both serum and urine exosomes from urothelial carcinoma patients compared to healthy donors. The high levels of circPRMT5 in serum and urinary exosomes were positively associated with lymph node metastasis and advanced tumor progression, suggesting that circPRMT5 might be a prognostic biomarker in urothelial carcinoma. In addition, it was found that other circRNAs, such as hsa_circ_0006633 [167], hsa_circ_0000520 [168], hsa_circ_0000673 [169], hsa_circ_0001017 [170], hsa_circ_0061276 [170], circ-TTC17 [171], circ-LDLRAD3 [172], hsa_circ_0001785 [173], hsa_circ_0001445 [174], hsa_circ_0000181 [175], hsa_circ_0013958 [176] and hsa_circ_0000285 [177, 178], were also detectable in plasma, serum or exosomes and could distinguish patients with cancer from healthy controls and were potential valuable biomarkers in cancer (Table 3).

\section{Conclusions}

CircRNAs were previously thought to represent errors during the process of RNA splicing. Fortunately, in the past few years, accumulating evidence has illustrated the significant regulatory effects of circRNAs on pathophysiologic processes, including tumorigenesis. CircRNAs are now regarded as a class of abundant, stable, diverse and conserved RNA molecules with a range of activities, including sponge, translation, splicing and regulation. The functions of circRNAs in cancer are gaining considerable interest and have become a focus of cancer research. In this review, we briefly summarized the recent advances regarding circRNAs in the hallmarks, stemness, resistance to therapy, and the possibility as biomarkers for cancer.

These research endeavors into circRNAs expand our understanding of eukaryotic transcription participants and their important roles in organisms, especially in cancer. The stability, conservatism, universality, and specificity of circRNAs make it to be a potential valuable prognostic and diagnostic biomarker for cancer, and the functions and regulatory roles that circRNAs play in tumor cells make it possible to be a target for the treatment of cancer. However, the study of circRNAs in cancer remains in its infancy. CircRNAs are far from being able to be incorporated into clinical practice, and there are still fundamental problems necessitating further investigation in this field. For example, there is an urgent need to develop a common standardized naming system for circRNA research. In addition, further investigation is needed regarding the precise mechanisms, other than those of miRNA sponge activity, of circRNAs underlying the initiation and progression of cancer. Furthermore, more controlled and large-scale clinical studies are required before cancer-specific circRNAs can be recommended for diagnosis and treatment. An advanced understanding of circRNA will provide beneficial insights and generate new hypotheses regarding cancer pathogenesis. We hope that the appropriate and precise use of circRNAs in clinical applications might eventually create breakthroughs for cancer therapy in the near future.

\section{Abbreviations \\ 3'-UTR: 3'-untranslated region; ABCB1: ATP-binding cassette B1; AKT: Protein kinase B; As-HaCaT: Arsenite-treated HaCaT; AUC: Area under curve; BAX: BCL2-associated X Protein; BC: Breast cancer; Bca: Bladder cancer; bcl- 2: B-cell lymphoma-2; BCSCs: Breast CSCs; CCNE1: Cyclin E1; CDK: Cyclin- dependent kinase; CDR1as: Cerebellar degeneration-related protein 1 anti- sense RNA; ceRNA: Competing endogenous RNA; circ-Amotl1: CircRNA derived from angiomotin-like1; CircRNAs: Circular RNAs; ciRNA: Circular intronic RNA; CML: Chronic myelogenous leukaemia; CRC: Colorectal cancer; CSCs: Cancer stem cells; DNMT1: DNA methyltransferase 1; DOCK1: Dedicator of cytokinesis 1; ecircRNA: Exonic circRNA; ECM: Extracellular matrix; EGFR: Epidermal growth factor receptor; ElciRNA: Exon-intron circRNA; EIF3J: Eukaryotic translation initiation factor 3 subunit J; EMT: Epithelial- mesenchymal transition; EZH2: Enhancer of zeste homolog 2; FLI1: Friend leukemia virus integration 1; Foxo4: Forkhead Box O 4; GC: Gastric cancer; HPSE: Heparanase; HuR: Human antigen R/ELAV-like protein 1; IGF1R: Insulin- like growth factor I receptor; IRES: Internal ribosome entry site; ITGB8: Integrin subunit beta 8; LSCC: Laryngeal squamous cell carcinoma; MREs: miRNA response elements; MYLK: Myosin Light Chain Kinase; NSCLC: Non-small cell lung cancer; nt: Nucleotide; ORF: Open reading frame; OS: Osteosarcoma; PAIP2: Polyadenylate-binding protein-interacting protein 2; PD-L1: Programmed death-ligand 1; PIK3CD: Phosphatidylinositol-4,5- bisphosphonate 3-kinase, catalytic subunit delta gene; PRC2: Polycomb- repressive complex 2; PTEN: Phosphatase and tensin homolog deleted on chromosome ten; ROCK1: Rho-associated protein kinase 1; Smad: Mothers against decapentaplegic; snRNPs: Small nuclear ribonucleic proteins; TDP cells: CD133 + CD44+ CSCs; TERT: Telomerase reverse transcriptase; TGF- $\beta$ : Transforming growth factor- $\beta$; TIF1Y: Transcriptional intermediary factor 1 $\gamma_{;}$TKI: Tyrosine kinase inhibitor; VEGF: Vascular endothelial growth factor; VEGFR: Vascular endothelial growth factor receptor; YAP1: Yes-associated protein 1; YY1: Yin Yang-1}

\section{Acknowledgements}

We thank Dr. Kunjian Peng for the helpful discussion.

\section{Funding}

This work is supported by grants from the National Natural Scientific Foundation of China (81802947), the Natural Science Foundation of Hunan Province (2019JJ50968, 2019JJ50358, 2017JJ2173, 2018JJ3314), Health and 
Family Planning Commission of Hunan Province (B20180545, C2019074), Changsha Science and Technology Board (kq1801110, kq1706045).

\section{Availability of data and materials Not applicable.}

\section{Authors' contributions}

$M S, Y X, J M, Y T, B T, Y Z, X L, Z W, D S, Y Z, H W, Q L$ and $W W$ collected the related paper and drafted the manuscript. MS, YX, JM, QL and WW participated in the design of the review and draft the manuscript. All authors read and approved the final manuscript.

\section{Ethics approval and consent to participate}

Not applicable.

\section{Consent for publication}

Not applicable.

\section{Competing interests}

The authors declare that they have no competing interests.

\section{Publisher's Note}

Springer Nature remains neutral with regard to jurisdictional claims in published maps and institutional affiliations.

\section{Author details \\ 'Department of the 2nd Department of Thoracic Surgery, Hunan Cancer Hospital and The Affiliated Cancer Hospital of Xiangya School of Medicine, Central South University, Changsha, Hunan 410013, People's Republic of China. ${ }^{2}$ Hunan Key Laboratory of Translational Radiation Oncology, Hunan Cancer Hospital and The Affiliated Cancer Hospital of Xiangya School of Medicine, Central South University, Changsha, China. ${ }^{3}$ Department of Pharmacy, Xiangya Hospital of Xiangya School of Medicine, Central South University, Changsha, Hunan 410001, People's Republic of China. ${ }^{4}$ Department of the Central Laboratory, Hunan Cancer Hospital and The Affiliated Cancer Hospital of Xiangya School of Medicine, Central South University, Changsha, Hunan 410013, People's Republic of China.}

\section{Received: 4 December 2018 Accepted: 13 March 2019}

\section{Published online: 18 April 2019}

\section{References}

1. Chen LL, Yang L. Regulation of circRNA biogenesis. RNA Biol. 2015:12:381-8.

2. Sanger HL, Klotz G, Riesner D, Gross HJ, Kleinschmidt AK. Viroids are singlestranded covalently closed circular RNA molecules existing as highly basepaired rod-like structures. Proc Natl Acad Sci U S A. 1976;73:3852-6.

3. Hsu MT, Coca-Prados M. Electron microscopic evidence for the circular form of RNA in the cytoplasm of eukaryotic cells. Nature. 1979;280:339-40.

4. Kos A, Dijkema R, Arnberg AC, van der Meide PH, Schellekens H. The hepatitis delta (delta) virus possesses a circular RNA. Nature. 1986;323:558-60.

5. Salzman J, Gawad C, Wang PL, Lacayo N, Brown PO. Circular RNAs are the predominant transcript isoform from hundreds of human genes in diverse cell types. PLoS One. 2012;7:e30733.

6. Hansen $\mathrm{TB}$, Jensen $\mathrm{TI}$, Clausen BH, Bramsen JB, Finsen B, Damgaard CK, Kjems J. Natural RNA circles function as efficient microRNA sponges. Nature. 2013:495:384-8.

7. Memczak S, Jens M, Elefsinioti A, Torti F, Krueger J, Rybak A, Maier L, Mackowiak SD, Gregersen LH, Munschauer M, et al. Circular RNAs are a large class of animal RNAs with regulatory potency. Nature. 2013;495:333-8.

8. Jeck WR, Sorrentino JA, Wang K, Slevin MK, Burd CE, Liu J, Marzluff WF Sharpless NE. Circular RNAs are abundant, conserved, and associated with ALU repeats. RNA. 2013;19:141-57.

9. Salzman J, Chen RE, Olsen MN, Wang PL, Brown PO. Cell-type specific features of circular RNA expression. PLoS Genet. 2013;9:e1003777.

10. Bai $Y$, Zhang $Y$, Han B, Yang L, Chen X, Huang R, Wu F, Chao J, Liu P, Hu G, et al. Circular RNA DLGAP4 ameliorates ischemic stroke outcomes by targeting miR-143 to regulate endothelial-mesenchymal transition associated with blood-brain barrier integrity. J Neurosci. 2018;38:32-50.

11. Holdt LM, Stahringer A, Sass K, Pichler G, Kulak NA, Wilfert W, Kohlmaier A Herbst A, Northoff BH, Nicolaou A, et al. Circular non-coding RNA ANRIL modulates ribosomal RNA maturation and atherosclerosis in humans. Nat Commun. 2016:7:12429.

12. Zhao $Y$, Alexandrov PN, Jaber $V$, Lukiw WJ: Deficiency in the Ubiquitin Conjugating Enzyme UBE2A in Alzheimer's Disease (AD) is Linked to Deficits in a Natural Circular miRNA-7 Sponge (circRNA; ciRS-7). Genes (Basel). 2016; 7.

13. Liu Q, Zhang X, Hu X, Dai L, Fu X, Zhang J, Ao Y. Circular RNA related to the chondrocyte ECM regulates MMP13 expression by functioning as a MiR-136 'Sponge' in human cartilage degradation. Sci Rep. 2016;6:22572.

14. Zhao Z, Li X, Jian D, Hao P, Rao L, Li M. Hsa_circ_0054633 in peripheral blood can be used as a diagnostic biomarker of pre-diabetes and type 2 diabetes mellitus. Acta Diabetol. 2017;54:237-45.

15. Zhou Z, Jiang $R$, Yang $X$, Guo $H$, Fang $S$, Zhang $Y$, Cheng $Y$, Wang J, Yao $H$, Chao J. circRNA mediates silica-induced macrophage activation via HECTD1/ZC3H12A-dependent ubiquitination. Theranostics. 2018;8:575-92.

16. Geng $Y$, Jiang J, Wu C. Function and clinical significance of circRNAs in solid tumors. J Hematol Oncol. 2018;11:98.

17. Chen L, Zhang S, Wu J, Cui J, Zhong L, Zeng L, Ge S. circRNA 100290 plays a role in oral cancer by functioning as a sponge of the miR-29 family. Oncogene. 2017:36:4551-61.

18. Guarnerio J, Bezzi M, Jeong JC, Paffenholz SV, Berry K, Naldini MM, Lo-Coco $F$, Tay $Y$, Beck AH, Pandolfi PP. Oncogenic role of fusion-circRNAs derived from Cancer-associated chromosomal translocations. Cell. 2016;166:1055-6.

19. Liang HF, Zhang XZ, Liu BG, Jia GT, Li WL. Circular RNA circ-ABCB10 promotes breast cancer proliferation and progression through sponging miR-1271. Am J Cancer Res. 2017;7:1566-76.

20. Zhang Y, Liang W, Zhang P, Chen J, Qian H, Zhang X, Xu W. Circular RNAs: emerging cancer biomarkers and targets. J Exp Clin Cancer Res. 2017:36:152.

21. Zhang $M, X i n$ Y. Circular RNAs: a new frontier for cancer diagnosis and therapy. J Hematol Oncol. 2018;11:21.

22. Lasda E, Parker R. Circular RNAs: diversity of form and function. RNA. 2014; 20:1829-42

23. Guo JU, Agarwal V, Guo H, Bartel DP. Expanded identification and characterization of mammalian circular RNAs. Genome Biol. 2014;15:409.

24. Suzuki $H$, Tsukahara T. A view of pre-mRNA splicing from RNase $R$ resistant RNAs. Int J Mol Sci. 2014;15:9331-42.

25. Xia S, Feng J, Lei L, Hu J, Xia L, Wang J, Xiang Y, Liu L, Zhong S, Han L, He C. Comprehensive characterization of tissue-specific circular RNAs in the human and mouse genomes. Brief Bioinform. 2017:18:984-92.

26. Chen X, Fan S, Song E. Noncoding RNAs: new players in cancers. Adv Exp Med Biol. 2016:927:1-47.

27. Meng X, Li X, Zhang P, Wang J, Zhou Y, Chen M. Circular RNA: an emerging key player in RNA world. Brief Bioinform. 2017;18:547-57.

28. Chen I, Chen CY, Chuang TJ. Biogenesis, identification, and function of exonic circular RNAs. Wiley Interdiscip Rev RNA. 2015;6:563-79.

29. Li Z, Huang C, Bao C, Chen L, Lin M, Wang X, Zhong G, Yu B, Hu W, Dai L, et al. Exon-intron circular RNAs regulate transcription in the nucleus. Nat Struct Mol Biol. 2015:22:256-64

30. Zhang $Y$, Zhang $X O$, Chen $T$, Xiang JF, Yin QF, Xing YH, Zhu S, Yang L, Chen LL. Circular intronic long noncoding RNAs. Mol Cell. 2013;51:792-806.

31. Ashwal-Fluss R, Meyer M, Pamudurti NR, Ivanov A, Bartok O, Hanan M, Evantal N, Memczak S, Rajewsky N, Kadener S. circRNA biogenesis competes with pre-mRNA splicing. Mol Cell. 2014;56:55-66

32. Conn SJ, Pillman KA, Toubia J, Conn VM, Salmanidis M, Phillips CA, Roslan S, Schreiber AW, Gregory PA, Goodall GJ. The RNA binding protein quaking regulates formation of circRNAs. Cell. 2015;160:1125-34.

33. Shi L, Yan P, Liang Y, Sun Y, Shen J, Zhou S, Lin H, Liang X, Cai X. Circular RNA expression is suppressed by androgen receptor (AR)-regulated adenosine deaminase that acts on RNA (ADAR1) in human hepatocellular carcinoma. Cell Death Dis. 2017:8:e3171.

34. Fei T, Chen Y, Xiao T, Li W, Cato L, Zhang P, Cotter MB, Bowden M, Lis RT, Zhao SG, et al. Genome-wide CRISPR screen identifies HNRNPL as a prostate cancer dependency regulating RNA splicing. Proc Natl Acad Sci U S A. 2017; 114:E5207-15

35. Khan MA, Reckman YJ, Aufiero S, van den Hoogenhof MM, van der Made I, Beqqali A, Koolbergen DR, Rasmussen TB, van der Velden J, Creemers EE, Pinto YM. RBM20 regulates circular RNA production from the titin gene. Circ Res. 2016;119:996-1003.

36. Bartel DP. MicroRNAs: target recognition and regulatory functions. Cell. 2009;136:215-33.

37. Bartel DP. MicroRNAs: genomics, biogenesis, mechanism, and function. Cell. 2004;116:281-97. 
38. Thomas LF, Saetrom P. Circular RNAs are depleted of polymorphisms at microRNA binding sites. Bioinformatics. 2014;30:2243-6.

39. Zhong Y, Du Y, Yang X, Mo Y, Fan C, Xiong F, Ren D, Ye X, Li C, Wang Y, et al. Circular RNAs function as ceRNAs to regulate and control human cancer progression. Mol Cancer. 2018;17:79.

40. Hansen TB, Kjems J, Damgaard CK. Circular RNA and miR-7 in cancer. Cancer Res. 2013;73:5609-12.

41. Peng L, Chen G, Zhu Z, Shen Z, Du C, Zang R, Su Y, Xie H, Li H, Xu X, et al. Circular RNA ZNF609 functions as a competitive endogenous RNA to regulate AKT3 expression by sponging miR-150-5p in Hirschsprung's disease. Oncotarget. 2017:8:808-18.

42. You X, Vlatkovic I, Babic A, Will T, Epstein I, Tushev G, Akbalik G, Wang M, Glock C, Quedenau C, et al. Neural circular RNAs are derived from synaptic genes and regulated by development and plasticity. Nat Neurosci. 2015;18: 603-10.

43. Wang K, Long B, Liu F, Wang JX, Liu CY, Zhao B, Zhou LY, Sun T, Wang M, $\mathrm{Yu} T$, et al. A circular RNA protects the heart from pathological hypertrophy and heart failure by targeting miR-223. Eur Heart J. 2016;37:2602-11.

44. Wang L, Wei Y, Yan Y, Wang H, Yang J, Zheng Z, Zha J, Bo P, Tang Y, Guo X, et al. CircDOCK1 suppresses cell apoptosis via inhibition of miR196a5p by targeting BIRC3 in OSCC. Oncol Rep. 2018;39:951-66.

45. Abdelmohsen K, Panda AC, Munk R, Grammatikakis I, Dudekula DB, De S, Kim J, Noh JH, Kim KM, Martindale JL, Gorospe M. Identification of HuR target circular RNAs uncovers suppression of PABPN1 translation by CircPABPN1. RNA Biol. 2017;14:361-9.

46. Du WW, Yang W, Liu E, Yang Z, Dhaliwal P, Yang BB. Foxo3 circular RNA retards cell cycle progression via forming ternary complexes with p21 and CDK2. Nucleic Acids Res. 2016;44:2846-58.

47. Chen LL. The biogenesis and emerging roles of circular RNAs. Nat Rev Mol Cell Biol. 2016;17:205-11.

48. Wang $X$, Fang L. Advances in circular RNAs and their roles in breast Cancer. J Exp Clin Cancer Res. 2018;37:206.

49. Liu D, Mewalal R, Hu R, Tuskan GA, Yang X. New technologies accelerate the exploration of non-coding RNAs in horticultural plants. Hortic Res. 2017; 4:17031.

50. Legnini I, Di Timoteo G, Rossi F, Morlando M, Briganti F, Sthandier O, Fatica A, Santini T, Andronache A, Wade M, et al. Circ-ZNF609 is a circular RNA that can be translated and functions in Myogenesis. Mol Cell. 2017;66:22-37 e29.

51. Zhang M, Huang N, Yang X, Luo J, Yan S, Xiao F, Chen W, Gao X, Zhao K, Zhou $\mathrm{H}$, et al. A novel protein encoded by the circular form of the SHPRH gene suppresses glioma tumorigenesis. Oncogene. 2018;37:1805-14.

52. Yang Y, Gao X, Zhang M, Yan S, Sun C, Xiao F, Huang N, Yang X, Zhao K, Zhou $\mathrm{H}$, et al. Novel role of FBXW7 circular RNA in repressing glioma tumorigenesis. J Natl Cancer Inst. 2018;110.

53. Pamudurti NR, Bartok O, Jens M, Ashwal-Fluss R, Stottmeister C, Ruhe L, Hanan M, Wyler E, Perez-Hernandez D, Ramberger E, et al. Translation of CircRNAs. Mol Cell. 2017:66:9-21 e27.

54. Bird A. DNA methylation patterns and epigenetic memory. Genes Dev. 2002;16:6-21.

55. Lv JF, Hu L, Zhuo W, Zhang CM, Zhou HH, Fan L. Epigenetic alternations and cancer chemotherapy response. Cancer Chemother Pharmacol. 2016;77:673-84

56. Chen N, Zhao G, Yan X, Lv Z, Yin H, Zhang S, Song W, Li X, Li L, Du Z, et al. A novel FLI1 exonic circular RNA promotes metastasis in breast cancer by coordinately regulating TET1 and DNMT1. Genome Biol. 2018;19:218.

57. Margueron R, Reinberg D. The Polycomb complex PRC2 and its mark in life. Nature. 2011:469:343-9.

58. Su M, Xiao Y, Tang J, Wu J, Ma J, Tian B, Zhou Y, Wang H, Yang D, Liao QJ, Wang W. Role of IncRNA and EZH2 interaction/regulatory network in lung Cancer. J Cancer. 2018:9:4156-65.

59. Li B, Xie F, Zheng FX, Jiang GS, Zeng FQ, Xiao XY. Overexpression of CircRNA BCRC4 regulates cell apoptosis and MicroRNA-101/EZH2 signaling in bladder cancer. J Huazhong Univ Sci Technolog Med Sci. 2017:37:886-90.

60. Qu D, Yan B, Xin R, Ma T. A novel circular RNA hsa_circ_0020123 exerts oncogenic properties through suppression of miR-144 in non-small cell lung cancer. Am J Cancer Res. 2018:8:1387-402.

61. Yong W, Zhuoqi X, Baocheng W, Dongsheng Z, Chuan Z, Yueming S. Hsa_ circ_0071589 promotes carcinogenesis via the miR-600/EZH2 axis in colorectal cancer. Biomed Pharmacother. 2018;102:1188-94.

62. Hanahan D, Weinberg RA. The hallmarks of cancer. Cell. 2000;100:57-70.

63. Huang C, Zeng $X$, Jiang G, Liao X, Liu C, Li J, Jin H, Zhu J, Sun H, Wu XR. XIAP BIR domain suppresses miR-200a expression and subsequently promotes EGFR protein translation and anchorage-independent growth of bladder cancer cell. J Hematol Oncol. 2017;10:6

64. Sooro MA, Zhang N, Zhang P. Targeting EGFR-mediated autophagy as a potential strategy for cancer therapy. Int J Cancer. 2018;143:2116-25.

65. Sun X, Li J, Sun Y, Zhang Y, Dong L, Shen C, Yang L, Yang M, Li Y, Shen G, et al. miR-7 reverses the resistance to BRAFi in melanoma by targeting EGFR/IGF-1R/CRAF and inhibiting the MAPK and PI3K/AKT signaling pathways. Oncotarget. 2016;7:53558-70.

66. Yang Z, Xie L, Han L, Qu X, Yang Y, Zhang Y, He Z, Wang Y, Li J. Circular RNAs: regulators of Cancer-related signaling pathways and potential diagnostic biomarkers for human cancers. Theranostics. 2017;7:3106-17.

67. Peng L, Yuan XQ, Li GC. The emerging landscape of circular RNA ciRS-7 in cancer (review). Oncol Rep. 2015:33:2669-74.

68. Piwecka M, Glazar P, Hernandez-Miranda LR, Memczak S, Wolf SA, RybakWolf A, Filipchyk A, Klironomos F, Cerda Jara CA, Fenske P, et al. Loss of a mammalian circular RNA locus causes miRNA deregulation and affects brain function. Science. 2017;357.

69. Xu B, Yang T, Wang Z, Zhang Y, Liu S, Shen M. CircRNA CDR1as/miR-7 signals promote tumor growth of osteosarcoma with a potential therapeutic and diagnostic value. Cancer Manag Res. 2018;10:4871-80.

70. Yao W, Yan L, Han L, Ji X, Pan H, Liu Y, Yuan J, Yan W, Ni C. The CDR1as/ miR-7/TGFBR2 axis modulates EMT in silica-induced pulmonary fibrosis. Toxicol Sci. 2018.

71. Zhang Y, Sun L, Xuan L, Pan Z, Li K, Liu S, Huang Y, Zhao X, Huang L, Wang $Z$, et al. Reciprocal changes of circulating Long non-coding RNAs ZFAS1 and CDR1AS predict acute myocardial infarction. Sci Rep. 2016;6:22384.

72. Zhang $X$, Yang D, Wei Y. Overexpressed CDR1as functions as an oncogene to promote the tumor progression via miR-7 in non-small-cell lung cancer. Onco Targets Ther. 2018;11:3979-87.

73. Weng W, Wei Q, Toden S, Yoshida K, Nagasaka T, Fujiwara T, Cai S, Qin H, Ma Y, Goel A. Circular RNA ciRS-7-a promising prognostic biomarker and a potential therapeutic target in colorectal Cancer. Clin Cancer Res. 2017:23:3918-28.

74. Yang X, Xiong Q, Wu Y, Li S, Ge F. Quantitative proteomics reveals the regulatory networks of circular RNA CDR1as in hepatocellular carcinoma cells. J Proteome Res. 2017;16:3891-902.

75. Zeng $\mathrm{K}$, Chen X, Xu M, Liu X, Hu X, Xu T, Sun H, Pan Y, He B, Wang S. CircHIPK3 promotes colorectal cancer growth and metastasis by sponging miR-7. Cell Death Dis. 2018;9:417.

76. Zheng Q, Bao C, Guo W, Li S, Chen J, Chen B, Luo Y, Lyu D, Li Y, Shi G, et al. Circular RNA profiling reveals an abundant circHIPK3 that regulates cell growth by sponging multiple miRNAs. Nat Commun. 2016;7:11215.

77. Liang D, Wilusz JE. Short intronic repeat sequences facilitate circular RNA production. Genes Dev. 2014;28:2233-47.

78. Melissa Millard SO, Neamati N. Integrin targeted therapeutics. Theranostics. 2011:1:154-88.

79. LaPointe $V L$, Verpoorte A, Stevens MM. The changing integrin expression and a role for integrin beta8 in the chondrogenic differentiation of mesenchymal stem cells. PLoS One. 2013;8:e82035.

80. Li G, Yang H, Han K, Zhu D, Lun P, Zhao Y. A novel circular RNA, hsa circ 0046701, promotes carcinogenesis by increasing the expression of miR-142$3 p$ target ITGB8 in glioma. Biochem Biophys Res Commun. 2018;498:254-61.

81. Eilers M, Eisenman RN. Myc's broad reach. Genes Dev. 2008;22:2755-66.

82. Reyes-Gonzalez JM, Armaiz-Pena GN, Mangala LS, Valiyeva F, Ivan C, Pradeep S, Echevarria-Vargas IM, Rivera-Reyes A, Sood AK, Vivas-Mejia PE. Targeting c-MYC in platinum-resistant ovarian Cancer. Mol Cancer Ther. 2015;14:2260-9.

83. Gearhart J, Pashos EE, Prasad MK. Pluripotency redux--advances in stem-cell research. N Engl J Med. 2007;357:1469-72.

84. Yang Q, Du WW, Wu N, Yang W, Awan FM, Fang L, Ma J, Li X, Zeng Y, Yang $Z$, et al. A circular RNA promotes tumorigenesis by inducing c-myc nuclear translocation. Cell Death Differ. 2017:24:1609-20.

85. Gutschner T, Diederichs S. The hallmarks of cancer: a long non-coding RNA point of view. RNA Biol. 2012;9:703-19.

86. Downes CP, Ross S, Maccario H, Perera N, Davidson L, Leslie NR. Stimulation of PI 3-kinase signaling via inhibition of the tumor suppressor phosphatase. PTEN Adv Enzyme Regul. 2007:47:184-94.

87. Chen CY, Chen J, He L, Stiles BL. PTEN: Tumor Suppressor and Metabolic Regulator. Front Endocrinol (Lausanne). 2018;9:338.

88. Karimian A, Ahmadi Y, Yousefi B. Multiple functions of p21 in cell cycle, apoptosis and transcriptional regulation after DNA damage. DNA Repair (Amst). 2016;42:63-71 
89. Lodygin D, Menssen A, Hermeking $\mathrm{H}$. Induction of the Cdk inhibitor p21 by LY83583 inhibits tumor cell proliferation in a p53-independent manner. J Clin Invest. 2002;110:1717-27.

90. Yang C, Yuan W, Yang X, Li P, Wang J, Han J, Tao J, Yang H, Lv Q, Zhang W. Circular RNA circ-ITCH inhibits bladder cancer progression by sponging miR17/miR-224 and regulating p21. PTEN expression Mol Cancer. 2018;17:19.

91. Liu T, Liu S, Xu Y, Shu R, Wang F, Chen C, Zeng Y, Luo H. Circular RNA-ZFR inhibited cell proliferation and promoted apoptosis in gastric Cancer by sponging miR-130a/miR-107 and modulating PTEN. Cancer Res Treat. 2018; 50:1396-417.

92. Pan H, Li T, Jiang Y, Pan C, Ding Y, Huang Z, Yu H, Kong D. Overexpression of circular RNA ciRS-7 abrogates the tumor suppressive effect of miR-7 on gastric Cancer via PTEN/PI3K/AKT signaling pathway. J Cell Biochem. 2018; 119:440-6.

93. Liu Z, Huang S, Cao Y, Yao Y, Li J, Chen J, Jiang B, Yuan X, Xiang X, Xiong J, Deng J. YAP1 inhibits circRNA-000425 expression and thus promotes oncogenic activities of miR-17 and miR-106. Biochem Biophys Res Commun. 2018:503:2370-5.

94. Wang K, Degerny C, Xu M, Yang XJ. YAP, TAZ, and Yorkie: a conserved family of signal-responsive transcriptional coregulators in animal development and human disease. Biochem Cell Biol. 2009;87:77-91.

95. Park JH, Shin JE, Park HW. The role of hippo pathway in Cancer stem cell biology. Mol Cells. 2018;41:83-92.

96. Hosooka T, Ogawa W. A novel role for the cell cycle regulatory complex cyclin D1-CDK4 in gluconeogenesis. J Diabetes Investig. 2016;7:27-8

97. Xue J, Liu Y, Luo F, Lu X, Xu H, Liu X, Lu L, Yang Q, Chen C, Fan W, Liu Q. Circ100284, via miR-217 regulation of $E Z H 2$, is involved in the arseniteaccelerated cell cycle of human keratinocytes in carcinogenesis. Biochim Biophys Acta Mol basis Dis. 1863;2017:753-63.

98. Guan Z, Tan J, Gao W, Li X, Yang Y, Li Y, Wang Q. Circular RNA hsa_circ_ 0016788 regulates hepatocellular carcinoma tumorigenesis through $\mathrm{miR}_{\bar{R}}$ 486/CDK4 pathway. J Cell Physiol. 2018;234:500-8.

99. Kai D, Yannian L, Yitian C, Dinghao G, Xin Z, Wu J. Circular RNA HIPK3 promotes gallbladder cancer cell growth by sponging microRNA-124. Biochem Biophys Res Commun. 2018;503:863-9.

100. Pierson J, Hostager B, Fan R, Vibhakar R. Regulation of cyclin dependent kinase 6 by microRNA 124 in medulloblastoma. J Neuro-Oncol. 2008;90:1-7.

101. Li L, Luo J, Wang B, Wang D, Xie X, Yuan L, Guo J, Xi S, Gao J, Lin X, et al. Microrna-124 targets flotillin-1 to regulate proliferation and migration in breast cancer. Mol Cancer. 2013;12:163.

102. Briscini L, Tonello C, Dioni L, Carruba MO, Nisoli E. BCl-2 and Bax are involved in the sympathetic protection of brown adipocytes from obesitylinked apoptosis. FEBS Lett. 1998;431:80-4.

103. Hortelano S, Bosca L. 6-Mercaptopurine decreases the BCl-2/Bax ratio and induces apoptosis in activated splenic B lymphocytes. Mol Pharmacol. 1997; 51:414-21.

104. Zhang R, Xu J, Zhao J, Wang X. Silencing of hsa_circ_0007534 suppresses proliferation and induces apoptosis in colorectal cancer cells. Eur Rev Med Pharmacol Sci. 2018;22:118-26.

105. Zhang H, Wang G, Ding C, Liu P, Wang R, Ding W, Tong D, Wu D, Li C, Wei Q, et al. Increased circular RNA UBAP2 acts as a sponge of miR-143 to promote osteosarcoma progression. Oncotarget. 2017:8:61687-97.

106. Deng N, Li L, Gao J, Zhou J, Wang Y, Wang C, Liu Y. Hsa_circ_0009910 promotes carcinogenesis by promoting the expression of miR-449a target IL6R in osteosarcoma. Biochem Biophys Res Commun. 2018;495:189-96.

107. Bian L, Zhi X, Ma L, Zhang J, Chen P, Sun S, Li J, Sun Y, Qin J. Hsa_circRNA_ 103809 regulated the cell proliferation and migration in colorectal cancer via miR-532-3p / FOXO4 axis. Biochem Biophys Res Commun. 2018;505:346-52.

108. Xu H, Zhang Y, Qi L, Ding L, Jiang H, Yu H. NFIX circular RNA promotes glioma progression by regulating miR-34a-5p via notch signaling pathway. Front Mol Neurosci. 2018;11:225.

109. Tasdemir E, Chiara Maiuri M, Morselli E, Criollo A, D'Amelio M, DjavaheriMergny M, Cecconi F, Tavernarakis N, Kroemer G. A dual role of p53 in the control of autophagy. Autophagy. 2008;4:810-4.

110. Du WW, Yang W, Li X, Awan FM, Yang Z, Fang L, Lyu J, Li F, Peng C, Krylov $\mathrm{SN}$, et al. A circular RNA circ-DNMT1 enhances breast cancer progression by activating autophagy. Oncogene. 2018;37:5829-42.

111. Chang ACY, Chang ACH, Kirillova A, Sasagawa K, Su W, Weber G, Lin J, Termglinchan V, Karakikes I, Seeger T, et al. Telomere shortening is a hallmark of genetic cardiomyopathies. Proc Natl Acad Sci U S A. 2018;115: 9276-81.
112. Bryan TM, Englezou A, Gupta J, Bacchetti S, Reddel RR. Telomere elongation in immortal human cells without detectable telomerase activity. EMBO J. 1995; 14:4240-8

113. Petrova OA, Mantsyzov AB, Rodina EV, Efimov SV, Hackenberg C, Hakanpaa J, Klochkov W, Lebedev AA, Chugunova AA, Malyavko AN, et al. Structure and function of the $\mathrm{N}$-terminal domain of the yeast telomerase reverse transcriptase. Nucleic Acids Res. 2018;46:1525-40.

114. Zhang XL, Xu LL, Wang F. Hsa_circ_0020397 regulates colorectal cancer cell viability, apoptosis and invasion by promoting the expression of the miR138 targets TERT and PD-L1. Cell Biol Int. 2017;41:1056-64.

115. Folkman J. Tumor angiogenesis: therapeutic implications. N Engl J Med. 1971;285:1182-6.

116. Roskoski R Jr. Vascular endothelial growth factor (VEGF) signaling in tumor progression. Crit Rev Oncol Hematol. 2007;62:179-213.

117. Su M, Huang J, Liu S, Xiao Y, Qin X, Liu J, Pi C, Luo T, Li J, Chen X, Luo Z. The anti-angiogenic effect and novel mechanisms of action of Combretastatin A-4. Sci Rep. 2016;6:28139.

118. Zhong Z, Huang M, Lv M, He Y, Duan C, Zhang L, Chen J. Circular RNA MYLK as a competing endogenous RNA promotes bladder cancer progression through modulating VEGFANEGFR2 signaling pathway. Cancer Lett. 2017:403:305-17.

119. Li Y, Zheng F, Xiao X, Xie F, Tao D, Huang C, Liu D, Wang M, Wang L, Zeng F, Jiang G. CircHIPK3 sponges miR-558 to suppress heparanase expression in bladder cancer cells. EMBO Rep. 2017;18:1646-59.

120. Jiang G, Zheng L, Pu J, Mei H, Zhao J, Huang K, Zeng F, Tong Q. Small RNAs targeting transcription start site induce heparanase silencing through interference with transcription initiation in human cancer cells. PLoS One. 2012;7:e31379.

121. Luan Q, Sun J, Li C, Zhang G, Lv Y, Wang G, Ma C, Gao T. Mutual enhancement between heparanase and vascular endothelial growth factor: a novel mechanism for melanoma progression. Cancer Lett. 2011;308:100-11.

122. Yang $P$, Qiu Z, Jiang Y, Dong L, Yang W, Gu C, Li G, Zhu Y. Silencing of CZNF292 circular RNA suppresses human glioma tube formation via the Wnt/beta-catenin signaling pathway. Oncotarget. 2016;7:63449-55.

123. Sporn MB. The war on cancer. Lancet. 1996;347:1377-81.

124. Yilmaz M, Christofori G. EMT, the cytoskeleton, and cancer cell invasion. Cancer Metastasis Rev. 2009;28:15-33.

125. Polyak K, Weinberg RA. Transitions between epithelial and mesenchymal states: acquisition of malignant and stem cell traits. Nat Rev Cancer. 2009;9:265-73.

126. Shibue T, Weinberg RA. EMT, CSCS, and drug resistance: the mechanistic link and clinical implications. Nat Rev Clin Oncol. 2017;14:611-29.

127. Kang Y, Massague J. Epithelial-mesenchymal transitions: twist in development and metastasis. Cell. 2004;118:277-9.

128. Liu AN, Zhu ZH, Chang SJ, Hang XS. Twist expression associated with the epithelial-mesenchymal transition in gastric cancer. Mol Cell Biochem. 2012; 367:195-203.

129. Meng J, Chen S, Han JX, Qian B, Wang XR, Zhong WL, Qin Y, Zhang H, Gao WF, Lei YY, et al. Twist1 regulates vimentin through Cul2 circular RNA to promote EMT in hepatocellular carcinoma. Cancer Res. 2018:78:4150-62.

130. Massague J. TGFbeta in Cancer. Cell. 2008;134:215-30.

131. Xue J, Lin X, Chiu WT, Chen YH, Yu G, Liu M, Feng XH, Sawaya R, Medema RH, Hung MC, Huang S. Sustained activation of SMAD3/SMAD4 by FOXM1 promotes TGF-beta-dependent cancer metastasis. J Clin Invest. 2014;124:564-79.

132. Wang L, Tong X, Zhou Z, Wang S, Lei Z, Zhang T, Liu Z, Zeng Y, Li C, Zhao J, et al. Circular RNA hsa_circ_0008305 (circPTK2) inhibits TGF-beta-induced epithelial-mesenchymal transition and metastasis by controlling TIF1gamma in non-small cell lung cancer. Mol Cancer. 2018;17:140.

133. He W, Dorn DC, Erdjument-Bromage H, Tempst P, Moore MA, Massague J. Hematopoiesis controlled by distinct TIF1gamma and Smad4 branches of the TGFbeta pathway. Cell. 2006;125:929-41.

134. Wang L, Yang H, Lei Z, Zhao J, Chen Y, Chen P, Li C, Zeng Y, Liu Z, Liu X, Zhang HT. Repression of TIF1gamma by SOX2 promotes TGF-beta-induced epithelialmesenchymal transition in non-small-cell lung cancer. Oncogene. 2016;35:867-77.

135. Liu RY, Zeng Y, Lei Z, Wang L, Yang H, Liu Z, Zhao J, Zhang HT. JAK/STAT3 signaling is required for TGF-beta-induced epithelial-mesenchymal transition in lung cancer cells. Int J Oncol. 2014;44:1643-51.

136. Heldin CH, Moustakas A. Role of Smads in TGFbeta signaling. Cell Tissue Res. 2012;347:21-36.

137. Zhang $X$, Luo P, Jing W, Zhou H, Liang C. Tu J: circSMAD2 inhibits the epithelial-mesenchymal transition by targeting miR-629 in hepatocellular carcinoma. Onco Targets Ther. 2018;11:2853-63. 
138. Zhang Y, Qiao WB, Shan L. Expression and functional characterization of FOXM1 in non-small cell lung cancer. Onco Targets Ther. 2018;11:3385-93.

139. Zhang Y, Ye X, Chen L, Wu Q, Gao Y, Li Y. PARI functions as a new transcriptional target of FOXM1 involved in gastric cancer development. Int J Biol Sci. 2018;14:531-41.

140. Xiao Z, Jia Y, Jiang W, Wang Z, Zhang Z, Gao Y. FOXM1: a potential indicator to predict lymphatic metastatic recurrence in stage IIA esophageal squamous cell carcinoma. Thorac Cancer. 2018;9:997-1004.

141. Chen Q, Zhang J, He Y, Wang Y. Hsa_circ_0061140 knockdown reverses FOXM1-mediated cell growth and metastasis in ovarian Cancer through miR-370 sponge activity. Mol Ther Nucleic Acids. 2018;13:55-63.

142. Wang J, Li H. CircRNA circ_0067934 silencing inhibits the proliferation, migration and invasion of NSCLC cells and correlates with unfavorable prognosis in NSCLC. Eur Rev Med Pharmacol Sci. 2018;22:3053-60.

143. Zhou LH, Yang YC, Zhang RY, Wang P, Pang MH, Liang LQ. CircRNA_ 0023642 promotes migration and invasion of gastric cancer cells by regulating EMT. Eur Rev Med Pharmacol Sci. 2018;22:2297-303.

144. Li Y, Atkinson K, Zhang T. Combination of chemotherapy and cancer stem cell targeting agents: preclinical and clinical studies. Cancer Lett. 2017;396:103-9.

145. Dalerba P, Clarke MF. Cancer stem cells and tumor metastasis: first steps into uncharted territory. Cell Stem Cell. 2007;1:241-2.

146. Su M, Xiao Y, Ma J, Cao D, Zhou Y, Wang H, Liao Q, Wang W. Long noncoding RNAs in esophageal cancer: molecular mechanisms, functions, and potential applications. J Hematol Oncol. 2018;11:118.

147. Yan N, Xu H, Zhang J, Xu L, Zhang Y, Zhang L, Xu Y, Zhang F. Circular RNA profile indicates circular RNA VRK1 is negatively related with breast cancer stem cells. Oncotarget. 2017:8:95704-18.

148. Liu R, Shi P, Nie Z, Liang H, Zhou Z, Chen W, Chen H, Dong C, Yang R, Liu S, Chen C. Mifepristone suppresses basal triple-negative breast Cancer stem cells by Down-regulating KLF5 expression. Theranostics. 2016;6:533-44.

149. Wang J, Wu Y, Gao W, Li F, Bo Y, Zhu M, Fu R, Liu Q, Wen S, Wang B. Identification and characterization of CD133(+)CD44(+) cancer stem cells from human laryngeal squamous cell carcinoma cell lines. J Cancer. 2017;8:497-506.

150. Wu Y, Zhang Y, Niu M, Shi Y, Liu H, Yang D, Li F, Lu Y, Bo Y, Zhang R, et al. Whole-transcriptome analysis of CD133+CD144+ Cancer stem cells derived from human laryngeal squamous cell carcinoma cells. Cell Physiol Biochem. 2018;47:1696-710.

151. Talati PG, Gu L, Ellsworth EM, Girondo MA, Trerotola M, Hoang DT, Leiby B, Dagvadorj A, McCue PA, Lallas CD, et al. Jak2-Stat5a/b signaling induces epithelial-to-mesenchymal transition and stem-like cell properties in prostate Cancer. Am J Pathol. 2015;185:2505-22.

152. Sui H, Fan ZZ, Li Q. Signal transduction pathways and transcriptional mechanisms of $\mathrm{ABCB} 1 / \mathrm{Pgp}$-mediated multiple drug resistance in human cancer cells. J Int Med Res. 2012;40:426-35.

153. Bruhn O, Cascorbi I. Polymorphisms of the drug transporters ABCB1, ABCG2, $A B C C 2$ and $A B C C 3$ and their impact on drug bioavailability and clinical relevance. Expert Opin Drug Metab Toxicol. 2014;10:1337-54.

154. Kun-Peng Z, Xiao-Long M, Chun-Lin Z. Overexpressed circPVT1, a potential new circular RNA biomarker, contributes to doxorubicin and cisplatin resistance of osteosarcoma cells by regulating ABCB1. Int J Biol Sci. 2018;14:321-30.

155. Kapoor TM, Mayer TU, Coughlin ML, Mitchison TJ. Probing spindle assembly mechanisms with monastrol, a small molecule inhibitor of the mitotic kinesin, Eg5. J Cell Biol. 2000;150:975-88,

156. Maliga Z, Kapoor TM, Mitchison TJ. Evidence that monastrol is an allosteric inhibitor of the mitotic kinesin Eg5. Chem Biol. 2002:9:989-96.

157. Liu Y, Dong Y, Zhao L, Su L, Luo J. Circular RNAMTO1 suppresses breast cancer cell viability and reverses monastrol resistance through regulating the TRAF4/Eg5 axis. Int J Oncol. 2018;53:1752-62.

158. Cortes J, Kantarjian H. Chronic myeloid leukemia: sequencing of TKI therapies. Hematology Am Soc Hematol Educ Program. 2016;2016: $164-9$.

159. Pan Y, Lou J, Wang H, An N, Chen H, Zhang Q, Du X. CircBA9.3 supports the survival of leukaemic cells by up-regulating C-ABL1 or BCR-ABL1 protein levels. Blood Cells Mol Dis. 2018:73:38-44.

160. Chandran RK, Geetha N, Sakthivel KM, Aswathy CG, Gopinath P, Raj TVA, Priya G, Nair J, Sreedharan H. Genomic amplification of BCR-ABL1 fusion gene and its impact on the disease progression mechanism in patients with chronic myelogenous leukemia. Gene. 2018;686:85-91.

161. Cui X, Wang J, Guo Z, Li M, Liu S, Liu H, Li W, Yin X, Tao J, Xu W. Emerging function and potential diagnostic value of circular RNAs in cancer. Mol Cancer. 2018;17:123
162. Gong Y, Mao J, Wu D, Wang X, Li L, Zhu L, Song R. Circ-ZEB1.33 promotes the proliferation of human HCC by sponging miR-200a-3p and upregulating CDK6. Cancer Cell Int. 2018;18:116.

163. Chen S, Li T, Zhao Q, Xiao B, Guo J. Using circular RNA hsa_circ_0000190 as a new biomarker in the diagnosis of gastric cancer. Clin Chim Acta. 2017; 466:167-71.

164. Huang M, He YR, Liang LC, Huang Q, Zhu ZQ. Circular RNA hsa_circ_ 0000745 may serve as a diagnostic marker for gastric cancer. World J Gastroenterol. 2017;23:6330-8.

165. Zhao SY, Wang J, Ouyang SB, Huang ZK, Liao L. Salivary circular RNAs Hsa_ Circ 0001874 and Hsa_Circ 0001971 as novel biomarkers for the diagnosis of Oral squamous cell carcinoma. Cell Physiol Biochem. 2018;47:2511-21.

166. Chen X, Chen RX, Wei WS, Li YH, Feng ZH, Tan L, Chen JW, Yuan GJ, Chen SL, Guo SJ, et al. PRMT5 circular RNA promotes metastasis of urothelial carcinoma of the bladder through sponging miR-30c to induce epithelialmesenchymal transition. Clin Cancer Res. 2018;24:6319-30.

167. Lu R, Shao Y, Ye G, Xiao B, Guo J. Low expression of hsa_circ_0006633 in human gastric cancer and its clinical significances. Tumour Biol. 2017;39: 1010428317704175.

168. Sun H, Tang W, Rong D, Jin H, Fu K, Zhang W, Liu Z, Cao H, Cao X. Hsa_ circ_0000520, a potential new circular RNA biomarker, is involved in gastric carcinoma. Cancer Biomark. 2018;21:299-306.

169. Chang P, Wang F, Li Y. Hsa_circ_0000673 is down-regulated in gastric cancer and inhibits the proliferation and invasion of tumor cells by targetting miR-532-5p. Biosci Rep. 2018;38.

170. Li T, Shao Y, Fu L, Xie Y, Zhu L, Sun W, Yu R, Xiao B, Guo J. Plasma circular RNA profiling of patients with gastric cancer and their droplet digital RTPCR detection. J Mol Med (Berl). 2018:96:85-96.

171. Wang Q, Zhang Q, Sun H, Tang W, Yang L, Xu Z, Liu Z, Jin H, Cao X. CircTTC17 promotes proliferation and migration of esophageal squamous cell carcinoma. Dig Dis Sci. 2018.

172. Yang F, Liu DY, Guo JT, Ge N, Zhu P, Liu X, Wang S, Wang GX, Sun SY. Circular RNA circ-LDLRAD3 as a biomarker in diagnosis of pancreatic cancer. World J Gastroenterol. 2017;23:8345-54.

173. Yin WB, Yan MG, Fang X, Guo JJ, Xiong W, Zhang RP. Circulating circular RNA hsa_circ_0001785 acts as a diagnostic biomarker for breast cancer detection. Clin Chim Acta. 2018:487:363-8.

174. Zhang X, Zhou H, Jing W, Luo P, Qiu S, Liu X, Zhu M, Liang C, Yu M, Tu J. The circular RNA hsa_circ_0001445 regulates the proliferation and migration of hepatocellular carcinoma and may serve as a diagnostic biomarker. Dis Markers. 2018;2018:3073467.

175. Zhao Q, Chen S, Li T, Xiao B, Zhang X. Clinical values of circular RNA 0000181 in the screening of gastric cancer. J Clin Lab Anal. 2018;32:e22333.

176. Zhu X, Wang X, Wei S, Chen Y, Fan X, Han S. Wu G: hsa_circ_0013958: a circular RNA and potential novel biomarker for lung adenocarcinoma. FEBS J. 2017:284:2170-82

177. Chi BJ, Zhao DM, Liu L, Yin XZ, Wang FF, Bi S, Gui SL, Zhou SB, Qin WB, Wu DM, Wang SQ. Downregulation of hsa_circ_0000285 serves as a prognostic biomarker for bladder cancer and is involved in cisplatin resistance. Neoplasma. 2018.

178. Shuai M, Hong J, Huang D, Zhang X, Tian Y. Upregulation of circRNA_ 0000285 serves as a prognostic biomarker for nasopharyngeal carcinoma and is involved in radiosensitivity. Oncol Lett. 2018;16:6495-501.

Ready to submit your research? Choose BMC and benefit from:

- fast, convenient online submission

- thorough peer review by experienced researchers in your field

- rapid publication on acceptance

- support for research data, including large and complex data types

- gold Open Access which fosters wider collaboration and increased citations

- maximum visibility for your research: over $100 \mathrm{M}$ website views per year

At $\mathrm{BMC}$, research is always in progress.

Learn more biomedcentral.com/submission 